\title{
Defensive Strategies in the Quality Ladders
}

\author{
Ivan Ledezma *
}

November, 2008

\begin{abstract}
This paper studies theoretically and empirically the consequences of defensive strategies in R\&D races. Using a quality-ladders model, we focus on incumbents' strategies based on their private knowledge and capabilities. Market institutions determine R\&D incentives and whether the Arrow-replacement effect holds. Regulatory provisions reducing defensive strategies in business processes may indeed increase the incentives to carry out $\mathrm{R} \& \mathrm{D}$. This effect is more likely to be observed when the size of innovation is high. Using data of manufacturing industries belonging to 14 OECD countries, we test the expected higher impact of regulation on R\&D intensity in industries producing and using ICT.
\end{abstract}

Keywords: Innovative Leaders, R\&D Contest, Market Regulation, OECD Industry-level data.

JEL Code: L1, D2, O3

\section{Introduction}

Innovation not only implies the discovery of a new "improved" product. It is also a process influenced by rent seeking strategies aiming at consolidating leading business positions. The so-called Coca Cola "formula" or the know-how required to adapt ERP ${ }^{1}$ business applications are some usual examples which testify to the fact that particular features of manufactured products are R\&D strategies in themselves. Indeed, the specific way in which a new discovery is implemented and introduced into the market has consequences over further discoveries. As shown by several surveys, the appropriation of R\&D returns goes beyond patents and may consider secrecy, lead time and learning curve advantages and manufacturing complementarities (Levin et al., 1987; Nelson and Walsh, 2000). Even patents are used for different strategic purposes in innovative countries such as the US and Japan (Cohen et al., 2002). These empirical works on strategic protection are consistent with Crépon and Duguet's (1997) finding of negative R\&D externalities among French manufacturing firms in narrow defined industries, a result interpreted by the authors as the outcome of competitors' rivalry.

These findings suggest that firms protect the value of their innovations using a set of multiple strategies. It is argued in this paper that this multiplicity is important to understand the effect of competition on $\mathrm{R} \& \mathrm{D}$ incentives. If firms have several alternatives

\footnotetext{
*Université Paris 1 Panthéon-Sorbonne (Centre d'Economie de la Sorbonne) ledezma@pse.ens.fr

${ }^{1}$ Enterprise Ressource Planning information system
} 
to keep their profits, potential competition may not necessarily act as a "slack reducing device". The menace of new entrants can actually translate into defensive reactions of incumbents rather than "truly" innovative ones. The aim of this paper is to analyse the impact of these defensive behaviour on $R \& D$ effort and on the observed market structure. Particular attention is devoted to the extent to which market regulation can influence R\&D effort. We refer as defensive strategies those adopted by incumbents with the aim of protecting their business position from the risk of loosing the innovation contest. We theoretically show that, when such strategies are available, market regulation may have a positive impact on aggregate R\&D effort and firm renewal. Using industry- level data for a sample of OECD countries during 1987-2003, we provide evidence supporting our main predictions.

These results, to some extent controversial, can indeed be expected if one thinks in regulation as a device allowing to manage strategic behaviour and not simply as an entry cost without profitable counterpart. To illustrate this idea, we focus on the case where defensive strategies rely on the complexity involved in the new product. Complexity is understood in a broad sense to capture the degree in which the underlying business process integrates different elements and their multiple interactions. A new improved good introduced by a leading firm may require important upgrades on the whole supply chain (including production), which makes more difficult the task of challengers. The latter are compelled to yield a new business solution in the context of several disadvantages concerning learning, experience, lead time developing, lack of codification, etc. (for short knowledge ) as well as unfavourable conditions related to the need of new manufacturing complementarities, copyrights, agency and organisational issues, market access, etc.(for short capabilities). ${ }^{2}$ These difficulties reflect the asymmetries between a successful innovator and its competitors. ${ }^{3}$ If innovators are aware of their advantages they may incorporate new processes and components to influence the way in which knowledge can be reproduced. As a consequence, they can alter the path of innovation by introducing a "technological bias" that builds a barrier for their challengers.

In this context, the link between de jure and de facto dimensions of competition becomes controversial since the way through which defensive strategies are constrained (de jure) has an impact on the observed market structure (de facto). For instance, there is not clear consensus about which position should be adopted by antitrust authorities regarding horizontal mergers and acquisitions or, even, bundling. ${ }^{4}$ Those practices, indeed, may lead to dominant positions in terms of complementary assets (including non-tangibles) that enable a firm to block its rivals. Similar caveats apply to the patent policy design.

\footnotetext{
${ }^{2}$ Intel Inside has recently incorporated the hafnium, a new material allowing to concentrate more transistors into their microchips (45 nm processors). This requires manufacturing adaptations that give, at least for a while, the upper-hand of Intel over its rivals.

${ }^{3}$ Simulating a model of management search, Rivking (2001) shows that complexity can account for the difference between replication and imitation. At certain level of complexity, neither low nor high, the incumbent is able to replicate a succesfull strategy within the boundaries of the firm with much less difficulties than its competitors can imitate it. While Rivking's (2001) disentangle between different obstacles to imitation and the complexity of the search process itself, in our argument both notion are closelly related since higher obstacles imply a harder search of a new business solution.

${ }^{4}$ Concerning the different treatments of dominant firms' strategies (namely Microsoft, General Electric, Intel among others) in Europe and the US, The Economist summarises the issue in the title of the printed article of May 1st 2008: "Oceans Apart: Europe still seems to have less faith than America in the ability of the free market to tame monopolies".
} 
Besides antitrust institutions, some usually-called "market barriers" are in practice "rules of the game" that define the set of strategies allowing incumbents to protect their rents. Procedures of controls determine qualitatively the set of possibilities of the final product. Standards and certifications influence knowledge codification and its further reproduction. Thus, regulation partially shapes the properties of the business process and product containing the state-of-the-art knowledge and, as a consequence, the difficulties that a challenger faces in its own search process.

We present a quality-ladders model featuring these strategic concerns. ${ }^{5}$ The main contribution is to address endogenously technological R\&D advantages leading to innovative leaders. Our theoretical setting consider two main ingredients: (i) an endogenous choice of technological bias and (ii) a Stackelberg type game in which the incumbent leader has the first mover advantage. The way we model defensives strategies of technological bias seeks to keep the dynamic of the model as tractable as possible. Quality is represented as a vector whose Euclidean norm is upgraded at each step of innovation. For a given quality level (the Euclidean norm), the firm chooses, among multiple quality dimensions, the specific quality mix to be introduced into the market (the direction of the vector). Thus, the private knowledge of the incumbent enables it to introduce a technological bias in the product. Regulation is then modelled as the extent to which the cost of technological bias increases along with the change in the quality mix.

The Stackelberg building block is based on Barro and Sala-i-Martin (2004). In a Stackelberg game, outsiders can be driven away from R\&D races if the leader (incumbent) is able to make a commitment of high $R \& D$ investment. Since technological advantages are the source of R\&D profitability, regulation, by constraining the possibilities of technological bias, determines whether the leader's commitment is credible. Thus, the model offers an endogenous threshold that defines who innovates. If the leader firm is not credible, the Arrow replacement effect holds in the usual way: outsiders have more R\&D incentives than incumbents, because the latter must replace themselves. As a consequence, the potential entrants carry out all R\&D effort and an steady state equilibrium with continuous Schumpeterian replacement $(S R)$ takes place. In such equilibrium, the technological bias helps the incumbent to delay its ending date. On the contrary, if the leader firm can make a credible commitment, it will do all $R \& D$ and will remain in the market indefinitely in the context of a permanent monopolistic ( $P M)$ equilibrium. In the $S R$ equilibrium, regulation increases the share of labour allocated to $R \& D$ because it helps to reduce the deterring effect. Its effect depends positively on the size of the innovative steps. The intuition is that the size of innovations acts as a monopolistic premium modulating R\&D incentives. In the $P M$ equilibrium, if regulation increases, but not enough to avoid permanent monopolists, it reduces the global R\&D intensity since it consumes more labour in defensive activities whithout increasing the net expected reward for outsiders.

The possibility at the equilibrium of simultaneous R\&D participation of incumbent and outsiders is ex-ante discarded by the linear form of R\&D technologies, the standard

\footnotetext{
${ }^{5}$ The quality-ladders framework allows to study in a tractable maner the Schumpeterian notion of creative destruction as modelled by Aghion and Howitt (1992) and Segerstrom et al. (1990). The basic idea stems from the pioneer model of Grossman and Helpman (1991) where innovation improves the quality of goods. Outsider firms carry out risky R\&D investment and the successful innovator replaces the current incumbent and becomes the new monopolistic leader, who remains in the market until the next innovation takes place. Hence, each innovator "climbs" one step the quality-ladder in the industry. The discounted monopolistic profits are the reward for new innovators that "steal" the incumbent's rents.
} 
assumption. We empirically test the predictions assuming an smoothing approximation in which monopolists are replaced, even if with a low probability. Using several indicators of market regulation provided by the OECD over a sample of 14 industries belonging to 14 OECD countries, we find a positive effect of regulation on R\&D intensity that increases for high technological industries. These industries are usually seen as performing bigger innovative jumps. Thus, the evidence is consistent with the model's predictions. This result, somewhat surprising, is close to previous evidence at the industry level. Nicoletti and Scarpetta (2003) find a positive interaction between product market regulation and the proximity to the technological frontier to explain multifactor productivity growth. While the authors interpret their finding as a negative effect of regulation on the catchingup process, it can also be seen as a positive effect of regulation on industries operating close to the world technological frontier. Similarly, Amable et al. (2008) find no evidence of a negative effect of regulation on innovative performance close to the technological frontier. After several robustness checks, what remains is that the marginal effect of regulation on innovation tends to be positive at the leading edge. Inklaar et al. (2007) analyse several sources of multifactor productivity growth in service sectors. Excepting telecommunications, their results fail to show a robust negative effect of market barriers on productivity growth. On the contrary, Arnold et al. (2008) using firm-level data of OECD countries and industry-level data of regulation do find that regulation induce a negative effect on productivity, but only in ICT-using industries. Among them, their sample considers several service sectors which are not present in our manufacturing sample.

Theoretically, we link two type of works in the quality-ladders literature. The first one relates to defensive behaviour in innovation-based dynamics by considering deterring strategies that do not directly rely on innovation. Thoenig and Verdier (2003) show how globalisation, by increasing the threat of leapfrogging, induces firms to adopt a technical bias in production. Firms introduce tacitness in the knowledge embodied in production, but they do it at the cost of increasing their skill-labour intensity. This gives an endogenous explanation of the rise in the skill-premium after trade liberalisation. Closely related, Dinopoulos and Syropoulos (2007) highlight the role of "rent protecting activities" in quality upgrading innovation. Following this idea, incumbents spend resources in patent blocking, legal processes on copyrights and the like to preserve their rents. These activities are at the centre of an innovative dynamics with an endogenous steady-state growth rate without scale effects. In both cases, firms play simultaneously as in a NashCournot equilibrium and have symmetric technologies in R\&D. These assumption implies that leaders do not innovate because of the above-mentioned Arrow replacement effect.

The second type of model introduces the possibility of innovative leaders (Segerstrom, 2007; Barro and Sala-i-Martin, 2004-Chapter 7; Etro, 2008). This can be done thanks to the assumption of exogenous R\&D advantages in technologies either considering (a) decreasing returns in R\&D and Nash-Cournot equilibrium (Segerstrom, 2007) or (b) constant returns to scale in the R\&D technology and a Stackelberg type game (Barro and Sala-i-Martin, 2004). More generally, within the latter case, Etro (2008) shows that for several settings with Stcakelberg type games in which entry is endogenous, leaders tend to be more aggressive. This result namely holds for innovation contests with asymmetric exogenous technologies.

Our explanation links these models, by reproducing endogenous relative R\&D advantages thanks to the availability of defensive strategies. These advantages are a key element for the presence of innovative leaders in the standard context of constant returns 
to scale and Stackelberg type game. The rest of the paper is organised as follows. Section 2 presents the model and Section 3 the empirical findings. Finally, we briefly conclude in Section 4.

\section{The model}

The model has been constructed to illustrate the strategic interactions between incumbents and outsiders. For the sake of simplicity we formalise our argument using a semiendogenous quality-ladders model without scale effects. The basic setup is based on Li (2003), which generalises Segerstrom's (1998) framework to consider imperfect interindustry substitutability. To remove steady state scale effects, Li (2003) assumes that as quality improves new discoveries need more R\&D effort. At equilibrium the innovation rate will not depend on the size of labour allocated to $R \& D$ but on the rate of population growth. ${ }^{6}$. We begin the exposition of the model with the basic setup of consumption and production (Section 2.1). The core of the argument is then presented: the strategic use of private knowledge and capabilities (Sections 2.2 and 2.3) and the effects on aggregate R\&D effort at equilibrium (Section 2.4)

\subsection{Consumption: Instantaneous decisions}

Per capita utility at each time $t$ is given by the CES formulation:

$$
u(t)=\left[\int_{0}^{1} z(t, \omega)^{\frac{\sigma-1}{\sigma}} d \omega\right]^{\frac{\sigma}{\sigma-1}}
$$

Where $z(t, \omega) \equiv \sum_{j} \gamma^{j} d(j, t, \omega)$ is the sub-utility function associated to each industry. The demand for the good of quality $j$ at time $t$ in industry $\omega$ is denoted by $d(j, t, \omega)$. The term $\gamma^{j}$ captures the quality level $j$ of a given good, where $\gamma>1$ is a parameter representing the size of quality upgrade. Thus, for a given industry $z(t, \omega)$ captures a situation in which consumers preferences are ordered by the quality of the available varieties. To avoid confusions in notation, all round brackets, (), are reserved to the arguments of the functions of the model.

At any time, households allocate their consumption expenditure $E(t)$ seeking to maximise $u(t)$. This static problem can be separated in two components: a within-industry consumption decision and a between-industry one. Giving the utility function $z(t, \omega)$ for the quality varieties in each industry $\omega$, all intra-industry expenditure will focus on the good $j^{*}$ having the lowest quality-adjusted price

$$
j^{*}=\underset{(j)}{\arg \min }\left\{\frac{p\left(\gamma^{j}, t, \omega\right)}{\gamma^{j}}\right\}
$$

\footnotetext{
${ }^{6}$ This feature caracterises a second wave of quality-ladders models that solve problems of scale effects in the steady state growth (Segerstrom, 1998; Young, 1998), a property strongly contradicting empirical evidence found by Jones (1995): while resources allocated to R\&D increase exponentially in the longrun data, productivity growth remains almost constant. For a survey on the evolution of this type of schumpeterian models see Dinopoulos and Sener (2007).
} 
The between-industry problem concerns the allocation of total expenditure $E(t)$ among all $\omega \in[0,1]$. This consists of applying $z^{*}(t, \omega)$ to $(1)$ and maximising $u(t)$ subject to $\int_{0}^{1} p\left(j^{*}, t, \omega\right) d\left(j^{*}, t, \omega\right) d \omega=E(t)$, which leads to the well-known CES demands:

$$
d\left(j^{*}, t, \omega\right)=\frac{\delta\left(j^{*}, t, \omega\right)}{p\left(j^{*}, t, \omega\right)^{\sigma} \int_{0}^{1} \frac{\delta\left(j^{*}, t, \omega^{\prime}\right)}{p\left(j^{*}, t, \omega^{\prime}\right)^{1-\sigma}} d \omega^{\prime}} E(t)
$$

Where $\delta\left(j^{*}, t, \omega\right) \equiv \gamma^{j^{*}[\sigma-1]}$ is a quality level index. This demand function (2) reflects a key property of monopolistic competition: each firm (one per industry) is in competition with the whole economy. Indeed, using the utility based index price $P=$ $\left[\int_{0}^{1}\left[\frac{p\left(j^{*}, t, \omega^{\prime}\right)}{\gamma^{j *}}\right]^{1-\sigma} d \omega^{\prime}\right]^{\frac{1}{1-\sigma}}$ and noting $C(t) \equiv \frac{E(t)}{P}=u(t)$ the equivalent aggregate good accounting for $u(t),(2)$ is then equivalent to state:

$$
d\left(j^{*}, t, \omega\right)=\delta\left(j^{*}, t, \omega\right)\left[\frac{P}{p\left(j^{*}, t, \omega\right)}\right]^{\sigma} C(t)
$$

Hence, demand decreases along with the relative quality-adjusted price concerning a particular producer and the average of the economy summarised in $P$.

\subsubsection{Consumption: Intertemporal decisions}

Households are considered as identical dynastic families whose number of members grows at the exogenous rate $n>0$. Each member of a household supplies inelastically one unit of labour. Without loss of generality, initial population is set to 1 , so that the population at time $t$ is $L(t)=e^{n t}$. Using a subjective discount rate $\rho>n$, each dynastic family maximises its intertemporal utility

$$
U=\int_{0}^{\infty} e^{-[\rho-n] t} \log u(t) d t
$$

subject to the usual intertemporal budget constraint that links stock market gains, revenue and expenditure. Noting $\dot{\Delta} \equiv \frac{d \Delta}{d t}$ the infinitesimal variation for any variable $\Delta$, this constrain implies (in flows):

$$
\dot{a}(t)=w(t)+r(t) a(t)-E(t)-n a(t)
$$

Where $a(t)$ is the endowment of per capita financial assets. Its variation is decomposed into current wage income of the representative household member $w(t)$ plus stock market gains $r(t) a(t)$ minus expenditure $E(t)$. Between $t$ and $d t$, per capita financial assets need to be adjusted by population growth $n$. Since $u(t)=\frac{E(t)}{P}$ and each individual takes $P$ as given, the intertemporal program is equivalent to the maximisation of $U=\int_{0}^{\infty} e^{-(\rho-n) t} \log E(t) d t$ subject to (5). Denoting $\mu$ the shadow price of the dynamic constraint, the Hamiltonian can be written as: 


$$
H=e^{-(\rho-n) t} \log E(t)+\mu[w(t)+r(t) a(t)-E(t)-n a(t)]
$$

As in most Ramsey-intertemporal consumption, this problem is solved with the help of the transversality condition $\lim _{t \rightarrow \infty} \mu(t) a(t)=0$ and the optimality conditions $\frac{\partial H}{\partial E}=0$ $; \frac{\partial H}{\partial a}+\dot{\mu}=0$. Differencing the resulting relationship leads to the well-known intertemporal optimal rule:

$$
\frac{\dot{E}(t)}{E(t)}=r(t)-\rho
$$

\subsubsection{Producers and price setting}

Labour is the only factor in production and is used in a technology with constant returns to scale. Each firm producing the variety $\omega$ sells its output to all members of the representative household. Thus, the firm produces a quantity of $d\left(j^{*}, t, \omega\right) L(t)$, sells at price $p\left(j^{*}, t, \omega\right)$ and incurs a production cost $w(t) d\left(j^{*}, t, \omega\right) L(t)$. After normalising wages, $w(t)=1$, the profit of each producer is given by:

$$
\pi\left(j^{*}, t, \omega\right)=\left[p\left(j^{*}, t, \omega\right)-1\right] d\left(j^{*}, t, \omega\right) L(t)
$$

Standard monopolist profit maximisation leads to a markup over marginal costs: $p\left(j^{*}, t, \omega\right)=\frac{\sigma}{\sigma-1}$. However, the monopolist is also in competition with firms offering lower quality goods. Given the perfect substituability within industries, a limit pricing behaviour applies. Consider, namely, the firm laying one step behind the leader in the quality-ladder and whose best quality-adjusted price is $\frac{p\left(j^{*}-1, \omega, t\right)}{\gamma^{j^{*}-1}}=\frac{1}{\gamma^{j^{*}-1}}$ (i.e. its price equal its marginal cost). Assuming a tie-break rule by which a consumer facing similar quality-adjusted prices prefers the good with the highest quality, the leader firm will charge $p\left(j^{*}, \omega, t\right)=\gamma$ and get all demands.

The application of this intra-industry price setting will depend on the size of innovation $\gamma$ and the monopolist power $\frac{\sigma}{\sigma-1}$. If $\frac{\sigma}{\sigma-1}>\gamma$ firms will charge $p\left(j^{*}, \omega, t\right)=\gamma$. On the other hand, if $\frac{\sigma}{\sigma-1} \leq \gamma$ the leader is unconstrained to charge its optimal monopolistic price rule $p\left(j^{*}, \omega, t\right)=\frac{\sigma}{\sigma-1}$. ${ }^{7}$ Innovation in our framework suppose further quality upgrades of the same good. In this sense, is more plaussible to assume that the size of each upgrade is not as big enough to induce the innovator to adopt the same price behaviour than a monopolist having no outside competition. Therefore, we restrict $\frac{\sigma}{\sigma-1}>\gamma$ and consider the price setting $p\left(j^{*}, \omega, t\right)=p=\gamma$.

Putting demands (2) into leader profits (7) and using the fact that $p$ neither depends on $j^{*}$ nor on $\omega$ yields:

$$
\pi\left(j^{*}, \omega, t\right)=\frac{[p-1]}{p} \frac{\delta\left(j^{*}, \omega, t\right)}{Q(t)} E(t) L(t)
$$

\footnotetext{
${ }^{7}$ This is an interesting point concerning usual distinctions between radical $\left(\gamma \geqslant \frac{\sigma}{\sigma-1}\right)$ and non radical innovations $\left(\gamma<\frac{\sigma}{\sigma-1}\right)$. What should be stressed is that this distinction depends on the elasticity of substitution. Empirically, it is not clear what relevant elasticity of substitution should be considered. Moreover, one of the risk of defining radical innovation by using this criteria is that the definition of radical innovation may come from a lower economy-wide competition rather than the size of each step of technological upgrade.
} 
Where $Q(t) \equiv \int_{0}^{1} \delta\left(j^{*}, \omega, t\right) d \omega=\int_{0}^{1} \gamma^{j^{*}[\sigma-1]} d \omega$ is the average quality index. Thus, the monopolistic competition framework implies that firms compete in quality with the whole economy.

\section{$2.2 \quad R \& D$ technologies and quality improvements}

As in the standard quality-ladders setup, at time $t=0$, the state-of-the-art quality in each industry is $j=0$. We suppose that, at this initial stage, in each industry some producer(s) has (have) the knowledge to fabricate a good of quality $j=0$. Firms then engage in $R \& D$ races to discover a new version of the good $\omega$ that provides a level of quality $j=1$. More generaly, at each state-of-the-art quality level $j$, the successful innovator of the current R\&D race improves quality to the level $j+1$ and climbs the quality-ladder one step ahead. The above-exposed price setting implies that the successful innovator becomes the sole producer in the industry. Thus, each incumbent is also the monopolist and the leader of the industry. Differently from the standard setup, in our model the incumbent does not wait until the next innovator "steal" its rents, but seeks to deter its potential rivals and to remain in the market. This Section is devoted to set the underlying R\&D framework allowing for these mechanisms.

Since at this point we know the determinants of our main variables, we can simplify our subscript notation. This simplification can be done thanks to three characteristics of the model: (i) there is only one firm producing a positive quantity in an industry; (ii) the only difference among industries concerning state variables is the current state-of-the-art quality level $j$; and (iii) all endogenous variables depend on $t$ (except prices). Based on (i) and (ii), we summarise the couple $\left(j^{*}, \omega\right)$ into $j_{\omega}$, which indicates the current state-of-theart good produced by the leader of industry $\omega$. Thanks to (iii) we can further facilitate notations and drop the time index, keeping in mind the time dependency of the model.

\subsubsection{Quality dimensions}

The quality provided by a firm producing in industry $\omega$ is given by the quality vector $\vec{q}\left(j_{\omega}\right)=\left\{q_{1}\left(j_{\omega}\right), q_{2}\left(j_{\omega}\right) \ldots, q_{m}\left(j_{\omega}\right)\right\}$. These dimensions should be understood as concerning not only the fabricated good but also the whole business process involved in the provision of the good to the customer and related services (i.e. the integrated supply chain). The magnitude (level) of quality is summarised by the euclidean norm of the vector $\left\|\vec{q}\left(j_{\omega}\right)\right\|=\sqrt{\sum_{k=1}^{m} q_{k}^{2}\left(j_{\omega}\right)}$ and the quality mix by its direction (the angle of the vector), which reflect the quality composition. The quality state $j_{\omega}$ is the outcome of step-by-step innovations. Different mix concerning the same industry and quality level are just perfect substituable versions of the same product. In each industry, two different quality mix provide the same utility if their magnitude is equal. However, as we will see, direction matters for the innovator.

The magnitude of the quality vector is upgraded at each step by a factor of $\gamma$, the size of innovations. The quality provided by the state-of-the-art $j_{\omega}$ is thus defined as $\left\|\vec{q}\left(j_{\omega}\right)\right\|=\gamma^{j_{\omega}}$ 


\subsubsection{Asymmetries between incumbents and outsiders}

Given that, for a each good, consumers only care about quality level why should we expect a change in the quality mix? Two assumptions allow to understand this: (a) while outsiders competing in a $R \& D$ race take the current quality mix as given, the current successful innovator can change it; (b) outsiders take a time to acquire the knowledge and capabilities (complementary assets, property rights, etc.) to introduce a new dimension of quality into the new state-of-the-art product.

Assumption (a) seeks to capture the innovator's advantages arising from its private knowledge about the new product. Once the new discovery come off, the new blueprint is certainly known by the innovator. The leader firm now has the choice about what visible properties its product (and related services) should have in the market. Assumption (b) implies that outsiders can not immediately reproduce the state-of-art knowledge and solve their lack of capabilities. In a basic quality-ladders framework, outsiders "via inspection of goods on the market, learn enough about the state of knowledge to mount their own research efforts, even if the patent laws (or the lack of complete knowledge about best production methods) prevent them from manufacturing the current generation products" (Grossman and Helpman, 1991 p. 47). With assumption (b) we are specifying that the "lack of complete knowledge" comes from the way new dimensions of quality must be incorporated into the new product and the need of new solutions to overcome the barrier constructed by the incumbent.

\subsubsection{Outsiders' $R \& D$ and technological bias}

Outsiders carry out R\&D activities by using labour as input. R\&D is governed by a Poisson stochastic process: $\ell$ units of labour allocated to research during an interval of time $d t$ imply a probability of success $\Lambda_{0}\left(j_{\omega}+1\right) \ell d t$ of a new up-grade. We call R\&D productivity the augmenting factor of the probability of innovative success implied by one unit of labour in the $R \& D$ process. For the outsider, the R\&D productivity is defined as

$$
\Lambda_{0}\left(j_{\omega}+1\right) \equiv \frac{h A^{\xi}}{\delta\left(j_{\omega}+1\right)}
$$

Similarly to $\mathrm{Li}$ (2003), this R\&D productivity is a function of the upgrade endeavoured $\left(j_{\omega}+1\right)$. The presence of $\frac{h}{\delta\left(j_{\omega}+1\right)}$, where $h$ is an exogenous technological parameter and $\delta\left(j_{\omega}+1\right)=\gamma^{\left[j_{\omega}+1\right][\sigma-1]}$, implies that, as the level of quality increases, the next improvement becomes harder and R\&D more costly.

The incidence of the quality mix on $\mathrm{R} \& \mathrm{D}$ is captured by $A$, the scalar product between the unitary vector $\vec{u}_{j_{\omega}}$ having the same direction than $\vec{q}\left(j_{\omega}\right)$ and the unitary vector $\vec{u}_{j_{\omega}-1}$, the one having the direction of the previous step $\vec{q}\left(j_{\omega}-1\right) .^{8}$ Let $\theta_{j_{\omega}}$ be the angle between vectors $\vec{q}\left(j_{\omega}\right)$ and $\vec{q}\left(j_{\omega}-1\right)$ (and, consequently, between $\vec{u}_{j_{\omega}}$ and $\left.\vec{u}_{j_{\omega}-1}\right)$. The term $A$ can be written as:

$$
A \equiv \vec{u}_{j_{\omega}} \times \vec{u}_{j_{\omega}-1}=\cos \left(\theta_{j_{\omega}}\right)
$$

Recall that the $\cos (\cdot)$ function is symmetric and monotonically decreases from 1 to 0 along with $\left|\theta_{j_{\omega}}\right| \in[0 ; \Pi / 2[$ (in $\Pi$ radians). Hence the change in the quality mix involved in

\footnotetext{
${ }^{8}$ The vector $\vec{u}_{j_{\omega}}$ is thus a vector of magnitude 1 whose angle (quality mix) equals the one of $\vec{q}\left(j_{\omega}\right)$.
} 
the upgrade of $j_{\omega}$ (i.e. $\theta_{j_{\omega}}$ ) implies that the R\&D difficulty faced by outsiders is augmented by a factor $A^{\xi}=\cos ^{\xi}\left(\theta_{j_{\omega}}\right)$. The instantaneous probability of innovation $I_{i}$ implied by the $\mathrm{R} \& \mathrm{D}$ effort of outsider $i$ is then:

$$
I_{i}=\ell_{i} \frac{h \cos ^{\xi}\left(\theta_{j_{\omega}}\right)}{\delta\left(j_{\omega}+1\right)}
$$

The advantage of using a vectorial representation of quality is that, between two wave of innovations, quality dimensions need not be specified. Between the previous and the current version of the product, represented by two vectors of $\mathbb{R}^{n}$, we just need to know the angle between them to model the technological bias. The effect of the latter will colapse to the scalar product among both vectors.

\subsubsection{The path of innovation}

Any time an innovative firm succeeds, it can add a new quality dimension to the current mix to introduce a bias in the path of innovation. One may assume an unbounded set of dimensions or an exogenous rate of discovery of them. An alternative assumption is to suppose the exogenous existence of $m+1$ dimensions and a certain degree of obsolescence of public knowledge: if during one wave of innovation a quality dimension have not been used, the old way to incorporate it into the product no longer applies.

Figure 1 illustrates this idea. Suppose three possible quality dimensions $(m+1=3)$ and that each good appears in the market with two of them. Let us start from the quality level $j$, which is totally based on dimension $q_{1}$ (implying a horizontal vector). Once the next innovative firm has succeeded in upgrading the quality level to $j+1$, it introduces a bias by including dimension $q_{2}$. The firm then produces the new version of the product with a quality vector having a direction $\theta_{j+1}$ far away from the previous one. By doing so, it increases the difficulty of the next $\mathrm{R} \& \mathrm{D}$ race (the one leading to the $j+2$ level) by a factor of $\cos ^{\xi}\left(\theta_{j_{\omega}+1}\right)$. Then, the next innovation occurs and improves the quality level to $j+2$. As in the figure, the new biased mix lies completely on the plan $q_{2}$ and $q_{3}$, dimension $q_{1}$ will be dropped $\left(q_{1}(j+2)=0\right)$. Now, if some obsolescence arises after one step of innovation, the next incumbent $(j+3)$ can use again the quality dimension $q_{1}$ as a source of bias. 


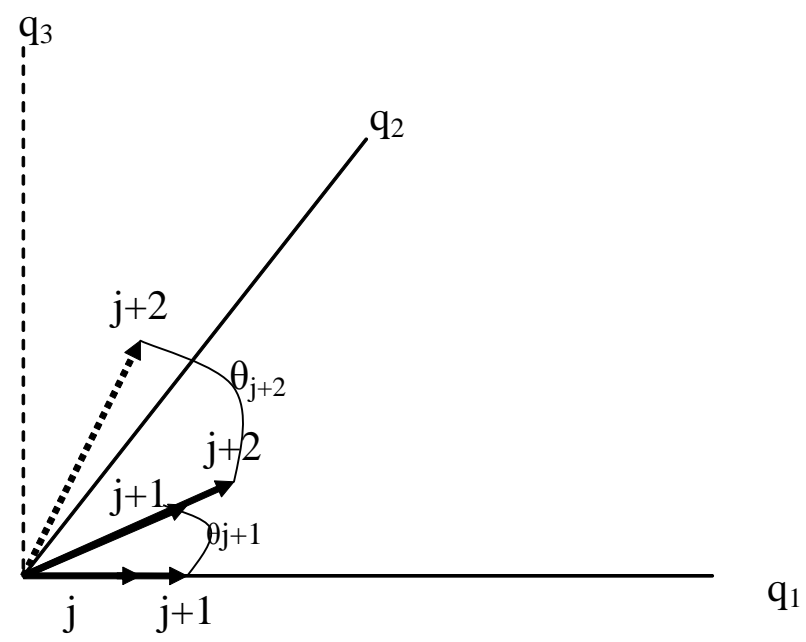

Figure 1. Quality dimensions and technological bias

\subsubsection{Leaders' R\&D technology and regulation}

If the incumbent firm is willing to do positive $R \& D$ effort it will not face the difficulty coming from bias. This firm has discovered the current state-of-the-art product and it is the sole producer that knows how to incorporate the new dimension in the manufacturing of the good. Hence, the leader R\&D productivity is just:

$$
\Lambda_{L}\left(j_{\omega}+1\right)=\frac{h}{\delta\left(j_{\omega}+1\right)}
$$

Any leader that changes the mix incurs a variable cost (in units of labour) of adapting the new version of the product with a new quality dimension. This cost is defined as:

$$
c\left(\theta_{j_{\omega}}, \psi\right) \equiv \frac{f}{\cos ^{\psi} \theta_{j_{\omega}} \Lambda_{L}\left(j_{\omega}\right)}
$$

We summarise in $\psi>1$ the extent to which regulation limits the new version of the product. Regulation implies a cost of technological bias that increases with the size of the bias (i.e. the change of the direction of the quality vector). This cost is all the more important that regulation is higher. Thus we modelise regulatory provisions as inducing fewer possibilities of complexity in the manufactured version of the improved product ${ }^{9}$.

$\Lambda_{L}\left(j_{\omega}\right)$ is the R\&D productivity of the leader firm in the former R\&D race $j_{\omega}$ (the one that it has won). Thus, the cost of introducing a technological bias in the new product diminishes with the R\&D productivity involved in its discovery. This also means that higher quality goods are more difficult "to bias" since R\&D productivity decreases with the quality level of the industry. Finally we include a non consequencial cost parameter $f<1$ to take into account the measure of units of labour required to activities relating to defensive strategies.

\footnotetext{
${ }^{9}$ Usual representations of regulation consider a fixed cost that limits the entry of firms. Here we are rather interested in regulatory barriers constraining the operation of firms.
} 


\subsection{Strategic behaviour}

Productive advantages obtained by the leader may allow it to deter any prospective entrant and become the only innovator. We now explore this possibility. In what follows, unless we explicitly specify the contrary, all R\&D productivity functions concern the next $R \& D$ race $j_{\omega}+1$. Thus we omit this index in the arguments of $\Lambda_{o}(\cdot)$ when dealing with $j_{\omega}+1$ and write the outsider's R\&D productivity as $\Lambda_{o}\left(\theta_{j_{\omega}}\right)=\Lambda_{L} \cos ^{\xi} \theta_{j_{\omega}}$, where $\left(\frac{\partial \Lambda_{o}}{\partial \theta_{j \omega}}<0\right)$.

\subsubsection{Firm's value}

In the outsider state a firm $i$ gets no profits and incurs an $R \& D$ cost of $\ell_{i o}$. Its value is denoted by $v_{o}$. Thanks to its R\&D effort, with instantaneous probability $\Lambda_{o}\left(\theta_{j_{\omega}}\right) \ell_{i o}$, the outsider may become the leader of the industry and get an optimal value denoted by $v_{L}\left(j_{\omega}+1\right)$. The Bellman equation of the outsider is then:

$$
r v_{o}=-\ell_{i o}+\Lambda_{o}\left(\theta_{j_{\omega}}\right) \ell_{i o}\left[v_{L}\left(j_{\omega}+1\right)-v_{o}\right]
$$

Putting $v_{o}=0$, one verifies that outsiders carry out a positive and finite amount of R\&D only when:

$$
v_{L}\left(j_{\omega}+1\right)=\frac{1}{\Lambda_{o}\left(\theta_{j_{\omega}}\right)}
$$

This is equivalent to state the equality between the expected value of innovation $v_{L}\left(j_{\omega}+1\right) \Lambda_{o}\left(\theta_{j_{\omega}}\right) \ell_{i o} d t$ and the R\&D investment during an infinitesimal interval of time $\ell_{i o} d t$. This equality applies when free entry occurs. The R\&D effort of the outsider for a given value of a successful innovation $v_{L}\left(j_{\omega}+1\right)$ is then:

$$
\ell_{i o}=\left\{\begin{array}{ll}
0 & \text { if } v_{L}\left(j_{\omega}+1\right)<\frac{1}{\Lambda_{o}\left(\theta_{j_{\omega}}\right)} \\
\infty & \text { if } v_{L}\left(j_{\omega}+1\right)>\frac{1}{\Lambda_{o}\left(\theta_{j_{\omega}}\right)} \\
\ell_{i o} \in \mathbb{R}^{+} & \text {if } v_{L}\left(j_{\omega}+1\right)=\frac{1}{\Lambda_{o}\left(\theta_{j_{\omega}}\right)}
\end{array}\right\}
$$

Let $\ell_{0}=\sum_{i} \ell_{i 0}$ be the whole amount of $\mathrm{R} \& \mathrm{D}$ carried out by outsiders. The Bellman equation of a (potential) innovative leader is

$$
r v_{L}\left(j_{\omega}\right)=\pi_{L}-\ell_{L}+\ell_{L} \Lambda_{L}\left[v_{L}\left(j_{\omega}+1\right)-v_{L}\left(j_{\omega}\right)\right]+\ell_{o} \Lambda_{o}\left(\theta_{j_{\omega}}\right)\left[v_{0}-v_{L}\left(j_{\omega}\right)\right]-c\left(\theta_{j_{\omega}}, \psi\right)
$$

If the leader carries out $R \& D$, with instantaneous probability $\ell_{L} \Lambda_{L}$ its optimal value $v_{L}\left(j_{\omega}\right)$ can jump to $v_{L}\left(j_{\omega}+1\right)$ thanks to a new discovery. With instantaneous probability $\ell_{o} \Lambda_{o}\left(\theta_{j_{\omega}}\right)$ the leader may be replaced by a successful outsider. In the meantime, the leader firm enjoys its monopolist profits $\pi_{L}$ and pays $\ell_{L}$ unit of labour for new discoveries as well as $c\left(\theta_{j_{\omega}}, \psi\right)$ units of labour for defensive strategies.

\subsubsection{The stackelberg game}

Since a leader firm is active in the market, its actions such as technology adoption, advertising and, of course, the quality mix choice, are visible. In an strategic framework, these actions can be seen as a commitment of R\&D effort. The consequence is that this 
commitment of the leader firm can be high enough to deter its rival. This structure is in line with a sequential stackelberg game in which the leader has the so called first mover advantage. Inmediately after innovating, the leader sets the quality mix $\theta_{j_{\omega}}$ in order to introduce a technological bias. This information is taken into account by outsiders in their decisions. Assume by the moment that the reaction function of outsiders respond negatively to the leader R\&D signal. The credibility of the leader's commitment depends its R\&D productivity advantages.

Proposition 1 A necessary condition to ensure that outsiders can be driven out of the $R \mathscr{E} D$ race is given by

$$
\Lambda_{L}\left[\frac{1}{\Lambda_{o}\left(\theta_{j_{\omega}}\right)}-\frac{\gamma^{-[\sigma-1]}}{\Lambda_{o}\left(\theta_{j_{\omega}-1}\right)}\right] \geq 1
$$

This credibility condition implies that the leader's REDD effort is irrespective of outsider actions.

Proof. See Appendix 5.1.1.

Inuitively, this condition defines a threshold for the R\&D productivity of the leader relative to that of the outsiders. Thanks to technoligical bias, this level can be attained. If this is the case, the constant returns of $R \& D$ investment imply that the leader can perform as much R\&D effort to put outsiders out of competition ${ }^{10}$. Thus, if (14) is ensured, the leading position value (13) can be written as:

$$
v_{L}\left(j_{\omega}\right)=\frac{\pi_{L}-c\left(\theta_{j_{\omega}}, \psi\right)-\ell_{L}+\ell_{L} \Lambda_{L} v_{L}\left(j_{\omega}+1\right)}{r+\ell_{L} \Lambda_{L}}
$$

Setting $\frac{\partial v_{L}\left(j_{\omega}\right)}{\partial \ell_{L}}=0$ allows to equating the marginal gain of the R\&D effort to its marginal cost.

$$
v_{L}\left(j_{\omega}+1\right)-v_{L}\left(j_{\omega}\right)=\frac{1}{\Lambda_{L}}
$$

As usually with constant returns, if (16) applies, the R\&D investment of the leader can be positive and finite. Putting the value of $v_{L}\left(j_{\omega}+1\right)$ implied by (16) into (15) yields the present optimal value of a permanent monopolist leader.

$$
v_{L}\left(j_{\omega}\right)=\frac{\pi_{L}-c\left(\theta_{j_{\omega}}, \psi\right)}{r}
$$

At equilibrium, the interest rate must verify (16) and (17), otherwise the leader carries out zero R\&D effort or an unbounded amount. Using the monopolist profits equation (7) we obtain:

$$
r=\frac{p-1}{p} \frac{E L\left[1-\gamma^{-[\sigma-1]}\right] h}{Q}
$$

\footnotetext{
${ }^{10}$ See Barro and Sala-i-Martin (2004) pp. 333-336 for this Stackelberg explanation.
} 
We are mainly interested in the steady state properties of the model. For the sake of presentation in (18) we assume that a constant value of $\theta_{j_{\omega}}=\theta$ exists. ${ }^{11}$ Now we can state the sufficiency of the credibility condition:

Proposition 2 For a constant value of $\theta_{j_{\omega}}=\theta$ the credibility condition (14) is sufficient to ensure zero outsiders' REBD effort. This condition can be expressed as:

$$
\cos ^{\xi} \theta \leq\left[1-\gamma^{-[\sigma-1]}\right]
$$

Proof. See Appendix 5.1.2.

Thus, when the bias is strong enough, i.e. $\cos ^{\xi} \theta \leq\left[1-\gamma^{-[\sigma-1]}\right]$, the leader firm does carries out research effort and the outcome is that the value of the next quality improvement will be lower than the R\&D cost incurred by outsiders. As a consequence, outsiders react by setting zero R\&D effort, meaning no replacement menace: $I_{o}=\ell_{o} \Lambda_{o}\left(\theta_{j_{\omega}}\right)=0$. In contrast, if credibility condition does not hold, the leader will do zero R\&D effort and will not innovate. All innovation will be done by outsiders. Nevertheless, since the leader firm can render the next $R \& D$ race harder it can delay its own replacement, which increases its value. In our particular setup the $R \& D$ advantage is endogenously determined by the technological bias. The possibilities of each scenario are thus endogenously determined.

\subsubsection{The choice of the bias}

Once the new innovative firm has succeeded and before producing it decides the visible features of the new version of the product. This new version may incorporate a new dimensions of quality, which generate a gap between private and public knowledge about the design of the product. The differences in the quality mix between the new manufactured version and the previous one is what we have called the technological bias $\left(\theta_{j_{\omega}}\right)$. This bias determines whether the incumbent becomes an innovative permanent leader firm or a non-innovative monopolist that can delay to some extent its date of replacement. Hence, the value of the incumbent leader can be discomposed into both situations:

$$
v_{L}\left(j_{\omega}\right)=\left\{\begin{array}{ll}
\frac{\pi_{L}-c\left(\theta_{j_{\omega}}, \psi\right)}{r+\ell_{o} \Lambda_{o}\left(\theta_{j \omega}\right)} & \text { if } \cos ^{\xi} \theta_{j_{\omega}}>\left[1-\gamma^{-[\sigma-1]}\right] \\
\frac{\pi_{L}-c\left(\theta_{j_{\omega}}, \psi\right)}{r} & \text { if } \cos ^{\xi} \theta_{j_{\omega}} \leq\left[1-\gamma^{-[\sigma-1]}\right]
\end{array}\right\}
$$

Note that before the leader takes the decision of bias, outsiders can potentially carry out research efforts and the free entry condition holds. Thus, the rationale of the decision of bias starts by considering the first case in (20). Since at this stage no technological advantage has been induced, the leader firm is not credible for the moment. The value is given by (13) for $\ell_{L}=0$. Here, the leader firm waits until a new successful innovator replace it. But it can still do better. For a given value of outsider's R\&D effort $\ell_{o}$, the discounted expected value of the leader will increase with the technical bias $\theta_{j_{\omega}}$. A higher R\&D difficulty means a lower probability of replacement and then a higher expected monopolist life. This decision of bias implies a cost of $c\left(\theta_{j_{\omega}}, \psi\right)$ units of labour which is increasing in $\psi$, the regulation parameter. Thus, the leader will choose a value of $\theta_{j_{\omega}}$ as high as possible, depending on regulation $\psi$. For a certain "low" level of regulation, this

\footnotetext{
${ }^{11}$ We show later that $\theta_{j_{\omega}+1}$ is constant for a constant outsider menace, which is the standard steady state condition of this kind of model.
} 
bias can be high enough to ensure the credibility condition as equality. In that case the economy jumps to a permanent monopolist framework.

Let us now derive this rationale analytically. Define $I_{o L} \equiv \ell_{o} \Lambda_{L}$ as the potential menace of outsiders, that is the probability of outsiders' innovative success in the absence of any bias $\left(\theta_{j_{\omega}}=0\right)$ (i.e. the same $R \& D$ productivity as the leader). We can then rewrite the bellman equation of the leader firm as

$$
r v_{L}\left(j_{\omega}\right)=\pi_{L}-I_{o L} \cos ^{\xi} \theta_{j_{\omega}} v_{L}\left(j_{\omega}\right)-c\left(\theta_{j_{\omega}}, \psi\right)
$$

Proposition 3 For a constant potential outsider menace $I_{o L}$, the optimal choice of $\theta_{j_{\omega}}$, is constant. Its value is given by

$$
\cos \theta=\left[\frac{\psi f}{\xi I_{o L}}\right]^{\frac{1}{\psi}}
$$

Proof. See Appendix 5.1.3.

As expected $\cos \theta$ decreases with $I_{o L}$. A higher potential menace of replacement implies a higher defensive strategy. Recalling that $I_{o}=I_{o L} \cos ^{\xi} \theta$, the probability of outsiders to succeed in innovation is then:

$$
I_{o}=I_{o L}^{\frac{\psi-\xi}{\psi}}\left[\frac{\psi f}{\xi}\right]^{\frac{\xi}{\psi}}
$$

Note that in the extreme case of $\psi \rightarrow \infty$, the outsiders'probability of innovation converges toward its potential $I_{o} \rightarrow I_{o L}$. Hence, a high level of regulation may (asymptotically) eliminate the bias $(\cos \theta \rightarrow 1)$.

In particular, $\psi$ can determine whether the credibility condition holds. Indeed, note that for agiven value of $I_{o L}$ regulation reduces the bias: $\frac{\partial \cos \theta}{\partial \psi}>0 .{ }^{12}$ If $\psi$ is particularly low, the technological bias implies that the $R \& D$ advantage of the leader firm relative to that of outsiders $\left(\frac{1}{\cos \theta}\right)$ can be high enough to allow it a credible commitment. In this case, the second part of the discontinuous function of the leader value (20) applies. The leader now enjoys permanent profits as an innovative monopolist. Since $\frac{\partial c\left(\theta_{j_{\omega}}, \psi\right)}{\partial \theta_{j_{\omega}}}>0$, a value of $\cos ^{\xi} \theta_{j_{\omega}}$ lower than $\left[1-\gamma^{-[\sigma-1]}\right]$ will only reduce $v_{L}\left(j_{\omega}\right)$. Therefore, the leader does not need further $R \& D$ advantages beyond the credibility point. As a consequence the optimal choice will be given by

$$
\cos ^{\xi} \theta=\left[1-\gamma^{-[\sigma-1]}\right]
$$

Equation (24), however, is not sufficient to analyse the regulation threshold alowing to separate both cases of (20). Actually $\cos \theta$ depends on the outsiders' potential menace. The latter needs to be computed at the steady state equilibrium.

Finally, it should be stressed that the reaction of zero R\&D effort of outsiders is a direct consequence of the linear $R \& D$ technology. With decreasing returns in the $R \& D$ technology, one has both players active in R\&D races (see Segerstrom, 2007). For the simplicity of the exposition we have adopted linear technologies.

\footnotetext{
${ }^{12}$ Taking $I_{o L}$ as given, $\frac{\partial \cos \theta}{\partial \psi}=\cos \theta\left[\frac{1-\log \left[\cos ^{\psi} \theta\right]}{\psi^{2}}\right]>0$ since $\log \left[\cos ^{\psi} \theta\right]<0$.
} 


\subsection{Global accounting and steady state equilibrium}

To sum up, the discontinuity of (20) implies two cases depending on the fulfillment of the credibility condition, which in turn depend on $\psi$. In the first case, outsiders do all $\mathrm{R} \& \mathrm{D}$ and the leader waits for its replacement (Schumpeterian replacement case). In the second situation, the leader may become the only innovator and enjoys permanent profits (permanent monopolist case). In this subsection we analyse the steady state macro equilibrium for each case.

The macro equilibrium for a continuum Schumpetrian replacement is given by the labour market clearing and the free entry condition. In a situation with a permanent monopolist, the free entry condition no longer holds. Instead, the steady state equilibrium condition arises from the interest rate (18) allowing a positive and finite amount of research.

\subsubsection{The Schumpeterian replacement case}

Labour market clearing needs the addition of labour used in research $L_{r}=\int_{0}^{1} \ell_{o}\left(j_{\omega}+1\right) d \omega$, manufacturing $L_{y}=\int_{0}^{1} L d\left(j_{\omega}+1\right) d \omega$ and defensive activities related to technological bias $L_{f}=\int_{0}^{1} c(\theta, \psi) d \omega$. We focus on the symmetric steady state equilibrium in which expenditure $E$ and outsiders innovative potential $I_{0 L}$ are constant. As a consequence, $\theta$ and $I_{0}$ are also constant. Using the probability of outsiders' innovative success (8), $I_{0 L}=\ell_{o} \Lambda_{L}=\frac{I_{o}}{\cos ^{\xi}(\theta)}$ and the definition the average quality $Q$ and $\delta\left(j_{\omega}+1\right)$, the demand for labour in research activities is given by:

$$
L_{r}=\frac{I_{o L} \gamma^{\sigma-1}}{h} Q
$$

After including consumers' demand $d\left(j_{\omega}+1\right)(2)$, labour required for manufacturing is:

$$
L_{y}=L \frac{E}{p}
$$

To obtain the labour demand for defensive activities, we use the definition of $c(\theta, \psi)$ written in (9) and the average quality $Q$. This leads to ${ }^{13}$ :

$$
L_{f}=\frac{f}{h \cos ^{\psi} \theta} Q
$$

We can now state the full employment condition clearing the labour market. This requires $L=L_{y}+L_{r}+L_{f}$, which is equivalent to:

$$
1=\frac{E}{p}+\frac{I_{o L} \gamma^{\sigma-1}}{h} \frac{Q}{L}+\frac{f}{h \cos ^{\psi} \theta} \frac{Q}{L}
$$

\footnotetext{
${ }^{13}$ Because industries are symmetric in probabilities, $\cos { }^{\psi} \theta$ (which depends on $I_{0 L}$ ) can be considered as a constant inside integrals.
} 
Recall that $\cos ^{\xi} \theta$ is stable when $I_{o L}$ is stable. Thus, in a equilibrium in which $I_{o L}$ and $E$ are constant $x \equiv \frac{Q}{L}$ must also be constant. As mentioned, prices and the rest of exogenous parameters do not depend on time. Thus, like in the standard schumpeterian model without scale effects and exogenous rate of growth, the average quality and the population must grow at the same rate:

$$
\frac{\dot{Q}}{Q}=\frac{\dot{L}}{L}=n
$$

The rate of growth of $Q$ is obtained in the usual way. Using the law of large numbers, the variation of average quality can be computed by adding the expected technological jump of each industry: $\dot{Q}=\int_{0}^{1} I_{o}\left[\delta\left(j_{\omega}+1\right)-\delta\left(j_{\omega}\right)\right] d \omega$. By applying the definition of $Q$ one obtains:

$$
\frac{\dot{Q}}{Q}=I_{o}\left[\gamma^{\sigma-1}-1\right]
$$

In steady state, condition (27) must hold. Thus, the innovation rate in steady state has the usual form:

$$
I_{o}=\frac{n}{\left[\gamma^{\sigma-1}-1\right]}
$$

The growth of the average quality $Q$ implies an steady-state utility growth of $\frac{\dot{u}(t)}{u(t)}=$ $\frac{n}{\sigma-1}$. This is the standard result obtained after putting demands (2) into the instantaneous utility (1) taking logs and differencing.

Back to our particular setup, the steady-state rate $I_{o}$ and equation (23) imply the following innovative potential of outsiders in steady state

$$
I_{o L}=\left[\frac{n}{\left[\gamma^{\sigma-1}-1\right]\left[\frac{\psi f}{\xi}\right]^{\frac{\xi}{\psi}}}\right]^{\frac{\psi}{\psi-\xi}}
$$

The steady-state bias in the Schumpeterian replacement case is obtained by putting (29) into (22):

$$
\cos ^{\xi} \theta=\left[\frac{\left[\gamma^{\sigma-1}-1\right] \psi f}{\xi n}\right]^{\frac{\xi}{\psi-\xi}}
$$

Again, here in steady state equilibrium, as $\psi \rightarrow \infty$ the bias decreases $\left(\cos ^{\xi} \theta \rightarrow 1\right)$. Thus regulation limits the possibilities of bias in steady state. As Figure 2 shows, upon a certain level of $\psi$ the economy can jump from the Schumpeterian equilibrium to the permanent monopolist one. The following proposition expose this.

Proposition 4 For $\psi>\xi$ there exists a unique level of regulation $\bar{\psi}$ defining the threshold between the Schumpeterian replacement and the permanent monopolistic cases involved in the value of the leader firm (20). 
Proof. See Appendix 5.1.4.

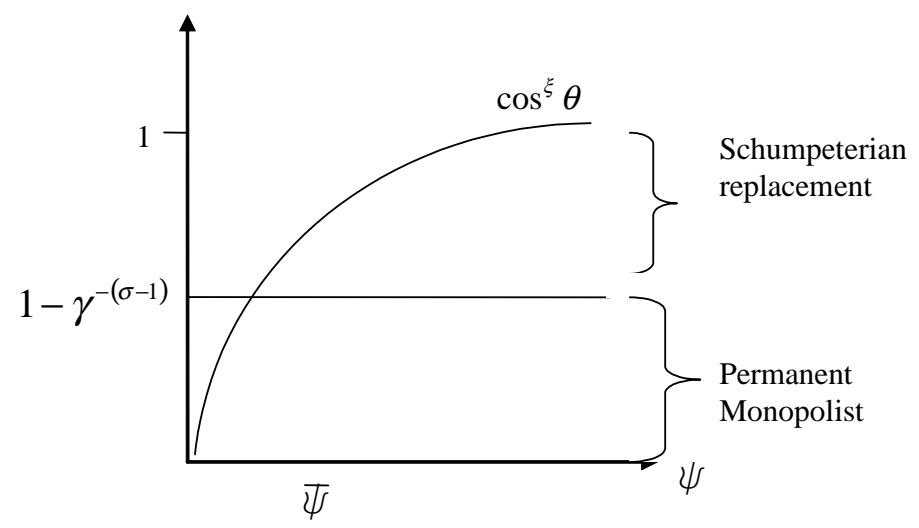

Figure 2. Threshold between continuous replacement and permanent monopolist equilibrium

We can analyse the role of regulation in steady-state by studying the share of labour allocated to research $s_{r} \equiv \frac{L_{r}}{L}$. This can be obtained from a system of two equations (the free entry condition (11) and (b) the labour market clearing (26)) with two unknowns: $x \equiv \frac{Q}{L}$ and $E$. For the free entry condition, the firm value is the one of the replacement case in (20). Both equations must be evaluated at the steady state values of $I_{o L}$ and $\cos \theta$. In addition, for a constant value of expenditure $E$, equation (6) must be verified and then $r=\rho$. Solving this system for $x$ and using $L_{r}$ as expressed by (25) one obtains:

$$
s_{r}=\frac{1}{\Gamma_{r e p}+\frac{\xi p}{\gamma^{\sigma-1}[p-1] \psi}}
$$

Where $\Gamma_{r e p} \equiv 1+\frac{\left[1-\gamma^{-[\sigma-1]}\right] \rho}{[p-1] n}+\frac{1}{\gamma^{\sigma-1}[p-1]}$. The following proposition can now be stated.

Proposition 5 In the Schumpeterian equilibirum, regulatory provisions $\psi$ increase the labour share allocated to $R \mathscr{E} D s_{r}$ and their effect is all the more important that the size of innovation $\gamma$ is bigger.

Proof. See Appendix 5.1.5. 


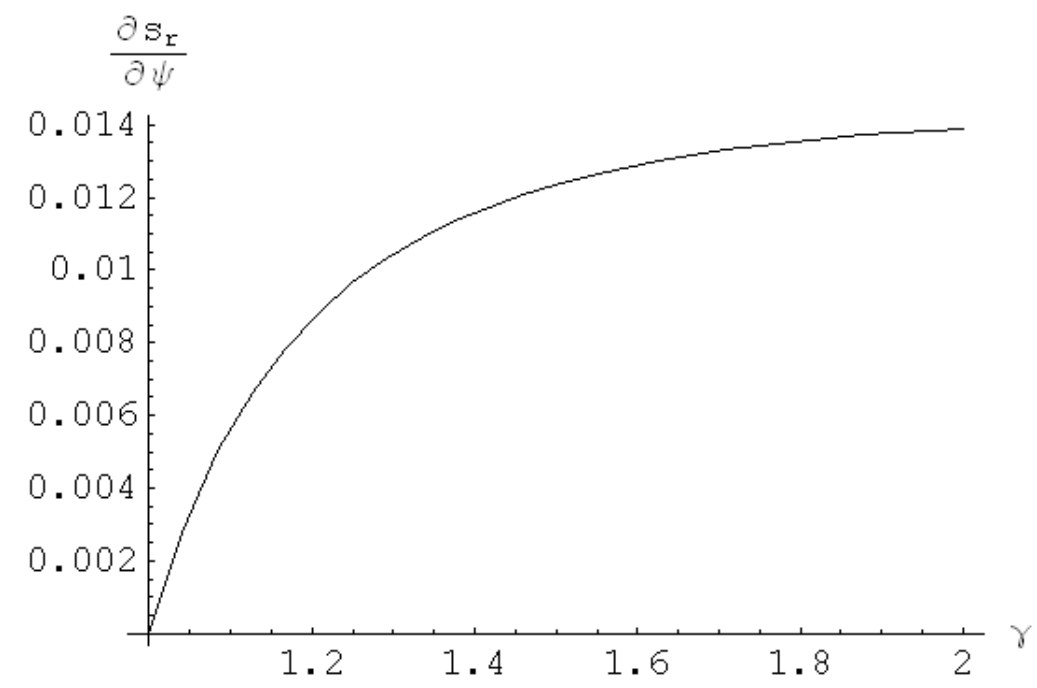

Figure 3. Size of innovation and the effect of regulation on

R\&D. (continuous replacement)

$$
\xi=0.5, n=2 \%, \sigma=2, \rho=5 \%, \psi=2
$$

At the steady state Schumpeterian equilibrium, which namely verifies the free entry condition, the aggregate of $\mathrm{R} \& \mathrm{D}$ investment decisions is computed, of course, once costs have been taken into account. Thus the dissuasive effect of the technological bias appears. Since R\&D becomes harder, at equilibrium, less firms will be willing to enter the R\&D race. The aggregate labour allocated to $R \& D$ then decreases.

The size of innovation affects the monopolistic setting price and also influences the difficulty of $R \& D$ races because it affects the cumulative cost of climbing the qualityladder. Concerning setting prices, the size of innovation acts as an increasing factor of the monopolist markup. This is a Schumpeterian incentive to R\&D captured by the multiplicative term $\frac{p}{p-1}=1-\frac{1}{\gamma}$. This monopolistic incentive modulate the $\mathrm{R} \& \mathrm{D}$ incentives coming from the reduction of bias. As Figure 3 shows, the effect of regulation is (postively) conditioned by the size of innovation.

\subsubsection{The permanent monopolist equilibrium}

In this equilibrium some minor adaptations for labour market clearing must be considered. First, the monopolist allocate labour to research without being affected by the bias. Its probability of innovative success is then $I_{L}=\ell_{L} \Lambda_{L}$. Second, the optimal choice of bias is now given by $\cos ^{\xi} \theta=\left[1-\gamma^{-[\sigma-1]}\right]$. The condition $L=L_{y}+L_{r}+L_{f}$ is thus stated as:

$$
1=\frac{E}{p}+\frac{I_{L} \gamma^{\sigma-1}}{h} \frac{Q}{L}+\frac{f}{h\left[1-\gamma^{-[\sigma-1]}\right]^{\frac{\psi}{\xi}}} \frac{Q}{L}
$$

As before, if expenditure and innovation rates are constant, we require $\frac{\dot{Q}}{Q}=\frac{\dot{L}}{L}=n$. Thus the steady-state rate of innovation remains the same: $I_{L}=\frac{n}{\left[\gamma^{\sigma-1}-1\right]}$. Moreover, since $E$ is constant, consumption growth is still given by $\frac{\dot{u}(t)}{u(t)}=\frac{n}{\sigma-1}$.

To compute the steady-state expenditure, we can not use the free entry condition. In the case of permanent rent, none outside the market is willing to participate in the 
$R \& D$ race. Instead, what equilibrates the economy is the interest rate (18). Putting this expression in the optimal path of expenditure (6) implies:

$$
E=\frac{\rho x}{\left[1-\gamma^{-[\sigma-1]}\right] h} \frac{p}{p-1}
$$

The steady-state share of labour allocated to R\&D $s_{r m}=\frac{L_{r}}{L}$ for the permanent monopolistic case can be obtaiend by substituting $E$, as defined by (33), into labour market clearing (32) for $I_{L}$ at the steady state. This yields:

$$
s_{r m}=\frac{1}{\left[\Gamma_{p e r}+\frac{f}{n\left[1-\gamma^{-(\sigma-1)}\right]^{\frac{\psi}{\xi}-1}}\right]}
$$

Where $\Gamma_{p e r} \equiv 1+\frac{\rho}{n[p-1]}$.

Proposition 6 In the permanent monopolist equilibrium, the level of regulation $\psi$ reduces the share of labour allocated to RED.

Proof. See Appendix 5.1.6.

Because of the discontinuity of the leader firm value, the optimal steady-state bias induced by the leader does not vary along with regulation. Indeed, the monopolist will not go beyond the level given by $\cos ^{\xi} \theta=\left[1-\gamma^{-[\sigma-1]}\right]$. If regulation increases, but not enough to ensure a continous monopolistic replacement, its effect translates into more labour required for defensive strategies. Since in this region $(\psi<\bar{\psi})$ the decision of labour allocated to defensive purposes does not consider its cost, it merely implies less labour to R\&D. In this equilibrium, the modulation made by the size of innovation on the effect of regulatiob is less clear. By simple inspection one notes that it depends on particular values of $\frac{\psi}{\xi}$.

\section{Evidence}

\subsection{Empirical strategy}

Our aim is to identify the effect of regulation on R\&D effort at the industry level. Following the model, the role of regulation depends on its level. If regulation is high enough, the continuous Schumpeterian replacement equilibrium arises and regulatory provisions do have an incitative effect on R\&D. On the contrary, if regulation is low enough to allow the credibility of the leader commitment, the permanent equilibrium arises and regulatory provisions have a negative effect on $R \& D$ effort.

Since information of outsiders (the potential entrants) is not available we cannot empirically differenciate between both situations. Moreover, as explained above, the outcome of zero R\&D effort comes from the choice of the standard linear technology in R\&D. In practice, monopolists are replaced, even if they remain for a long period of time. Indeed, as we are dealing with quality improvements within manufacturing, we should expect parameters values of $\sigma$ and $\gamma$ in line with a low level of $\left[1-\gamma^{-[\sigma-1]}\right]$. This means that a high level of bias $\theta$ should be required to ensure leader credibility. Thus, one may assume the "truly" permanent monopolistic case as an extreme possibility and suppose that sooner or later monopolists are replaced. 
Consequently, we should be mainly concerned with the Schumpeterian equilibrium. We then expect a positive effect of regulation on $R \& D$ effort, which is more likely to be observed for higher sizes of innovation. Data availability is also constraining in this respect. We suppose that high technology manufacturing (HT) industries make bigger innovative steps. In the sample, these industries are defined as 30-33 ISIC Rev-3 industries. This includes the information and communication technologies (ICT industries) and the manufacturing of medical precision and optical instruments. Results remain similar if one includes industries 29 (machinery and equipment) and motor vehicles (34), industries using intensively ICT technologies.

Therefore, we expect that, for these industries, the type of innovation especially allows for monopolistic incentives. If this is true, $R \& D$ incentives induced by regulation should be higher in HT industries relative to the rest. Let $y_{i t}$ be the measure of aggregate R\&D effort (labour share in the model) of industry $i$ at time $t$. We proxy R\&D effort with the $R \& D$ intensity of the industry measured as the $R \& D$ expenditure over value added. Denoting $R_{i t}$ the regulation proxy and $H T$ the dummy variable identifying HT industries, our regressions have the following specification:

$$
y_{i t}=\alpha_{1} R_{i t}+\alpha_{2} R_{i t} \times H T+\alpha_{3} H T+\alpha_{5} x_{i t}+\epsilon_{i t}
$$

Where $\epsilon_{i t}=\eta_{i}+\mu_{i t}, x_{i t}$ is a vector of controls. All variables are in natural logs (except $H T)$. The marginal effect of regulation can be computed as

$$
\frac{\partial E\left[y_{i t} / H T\right]}{\partial R_{i t}}=\alpha_{1}+\alpha_{2} H T
$$

If $H T=0$ then the marginal effect is $\alpha_{1}$ and reflects the effect of regulation on non-HT industries. When $H T=1$ the marginal effect is $\alpha_{1}+\alpha_{2}$. This means that $\alpha_{1}$ is also the effect of regulation which is common to HT and non-HT industries. Thus, $\alpha_{2}$ is the effect of regulation on $\mathrm{R} \& \mathrm{D}$ intensity in $\mathrm{HT}$ industries relative to non- $\mathrm{HT}$ ones.

Our model predicts a positive effect of regulation on R\&D intensity that increases with the size of innovation. Hence, we expect a positive and significant estimate $\widehat{\alpha}_{2}$. In other words, if an R\&D-boosting effect of regulation can be expected by our theoretical argumetns, it is more likely to be observed in the specificity of high technology industries. In absolute terms, the over all effect of regulation on R\&D intensity in HT industries will be given by $\widehat{\alpha}_{1}+\widehat{\alpha}_{2}$. While the significance of $\widehat{\alpha}_{2}$ can be obtained directly from the regressions, for $\widehat{\alpha}_{1}+\widehat{\alpha}_{2}$ we need to compute the joint significance (See Friedrich,

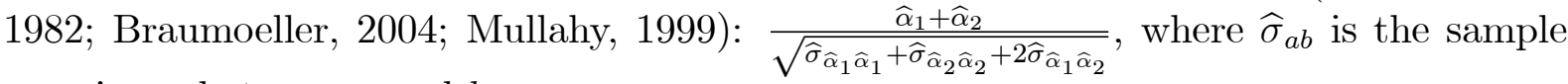
covariance between $a$ and $b$.

Since individuals units are manufacturing industries in different countries we expect a fixed component in the error term. The bias produced by this unobserved time-invariant heterogeneity can be eliminated by the Within Group estimator, at the cost of losing the information provided by $\widehat{\alpha}_{3}$. The Within Group estimator transforms the model by subtracting the sample period mean of each variable for each individual. This allows to eliminate $\eta_{i}$, but also all time-invariant variables such as HT. As our focus of interest is mainly $\widehat{\alpha}_{2}$ and $\widehat{\alpha}_{1}+\widehat{\alpha}_{2}$ we adopt this strategy. ${ }^{14}$

\footnotetext{
${ }^{14}$ Further insights about $H T$ can be learned by using the fixed effect vector decomposition (FEVD)
} 
Among controls $x_{i t}$ in (35) we consider (i) the lag of the closeness relative to the technological frontier; (ii) capital intensity ; (iii) innovation spill-overs (iv) financial deepness. The details of the data and sources is exposed below.

\subsection{Data}

We use the dataset containing information for 14 manufacturing industries across 14 OECD countries for the period running from 1987-2003. R\&D series are provided by the OECD ANBERD dataset. The sample period is given by the R\&D data availability (1987-2003). Our dependant variable, R\&D intensity is computed as R\&D expenditure over value added. The latter series are provided by the 60 -Industry database of the Groningen Growth and Development Centre (GGDC). We use a transversal deflation considering industry-level PPA for 1997 of Timmer, Ympa and van Ark (2006).

Indicators of regulation are provided by the OECD. The advantage of these indicators is that they rely on surveys concerning administrative practices seen as market barriers. We consider four indicators of regulation.

- PMR: It is an economy-wide indicator of product market regulation. PMR Is composed of a collection of inward- and outward-oriented indicators of market barriers at the national level. While close to regulatory practices its availability in time dimension is a drawback. It is only available for 1998 and 2003. The details of the construction of this indicators can be found in Conway et al. [2005]

- PMR-Public: An important component of PMR that measures the size and the scope of the public enterprise sector (PMR-Public). This proxy can capture different ways to conduct $\mathrm{R} \& \mathrm{D}$ between public and private actors and also the regulatory environment in R\&D activities.

- REGREF: It is an indicators of regulation of network sectors (telecoms, electricity, gas, post, rail, air passenger transport, and road freight). It is available in timesseries at the country level. As those sectors have been one of the main object of wider deregulation policies, they allow to capture the evolution of the competitive environment at the national level. Moreover, these sectors have a high interaction with manufacturing. Thus, regulation constraining the activity in network sectors may also have an impact on manufacturing operation.

- REGIMP: It captures the manufacturing "knock-on" effects of regulation in network, distribution services and finance on manufacturing. The main advantage of these indicators is that they are available in the form of panel (time-series cross-section) data . The methodology of REGIMP and REGREF is fully detailed in Conway and Nicoletti (2006)

developed by Plümper and Troeger (2007). It consists of three stages. First, a fixed model effect is estimated in order to measure $\eta_{i}$. The second stage correlates this measure with time-invariant variables, those that are eliminated in the usual fixed effect strategy. This step then decomposes $\eta_{i}$ into a part explained by time-invariant variables and an unexplainable one. The third stage re-estimates the model by OLS and includes the unexplainable error term accounted in the second step. This final step also controls for collinearity between time-varying and time-invariant variables and it adjusts the degrees of freedom. Results (not reported) do not change when we use this methodology. 
Among controls we consider:

- Closeness to the technological frontier: For a given period it is measured as the labour productivity of each country-industry couple relative to the highest one in the world in the same industry.

- Capital intensity: The ratio of deflated capital stock (from OECD STAN) to hours worked (GGDC)

- Innovation spill-overs: These externalities are captured by the R\&D intensity performed by the rest of the world in the same industry

- Financial deepness: Financial development indicator proxied by the ratio of total asset investment of institutional investors over GDP available from the OECD.

\subsection{Results}

Results of Within Group regressions are presented in Tables 1 to Table 4 for each regulation proxy. All regressions consider Huber-White corrected standard errors. Columns display a progressive inclusion of the explanatory variables. We start with the basic model considering regulation and $R \& D$ spillovers (column [1]). We then allow for a differentiated effect of regulation depending on the size of innovation,which is captured by the interaction between regulation and the dummy variable HT (column [2]). In line with recent works on innovation, the model in column [3] includes the proximity to the technological frontier. We use the lag of this variable in order to avoid (at least in part) reverse causality caveats. Finally, in column [4] we add the capital labour ratio and the financial deepness proxy. All models considers year dummies and individual fixed effects. Further, in the bottom part of each table we include the assessment of the overall effect of regulation on R\&D intensity in HT industries. This is computed as the marginal effect $\widehat{\alpha}_{1}+\widehat{\alpha}_{2}$ (equation 35) and its significance.

Table 1 shows the results corresponding to the regulation proxy REGREF related to regulatory provisions in network sectors (telecoms, electricity, gas, post, rail, air passenger transport, and road freight). Manufacturing industries are intermediate inputs of these seven services and also use them in their business process. In this sense, manufacturing production can be seen as subject to their regulation. In a more indirect way, this indicator also allows to capture the regulatory environment of an economy. Following this indicator, in our sample average, Greece and Italy appear as the most regulated countries. UK and US on the contrary are in the opposite extreme.

In the basic model of column [1], regulation has a positive and significative impact on $R \& D$ intensity. As expected, international $R \& D$ spillovers ( $R \& D$ intensity of the rest of the world in the same industry), have a positive and significant effect in column [1]. The same is true for the rest of regressions. The model in column [2] yields a positive and significant coefficient of the interaction between regulation and the dummy variable HT. Thus, relative to the rest of industries, the effect of regulation is higher in HT manufacturing. Confirming the model's prediction this interaction term is positive and significant in all specifications. On the other hand, regulation fails to account for a significant effect in non-HT industries (the estimated elasticity of REGREF alone).

The marginal effect, computed in the bottom part of Table 1, considers both (a) the effect of regulation that is common for HT and non-HT industries ( $\widehat{\alpha}_{1}$ in equation 35) 
and (b) the additional incentives of HT industries to carry out R\&D when regulation is increased $\left(\widehat{\alpha}_{2}\right.$ in equation 35). This marginal effect of regulation on R\&D intensity in $\mathrm{HT}$ industries is positive and significant in all regressions.

Controls present the expect sign. Capital labour ratio and financial assets over GDP have a positive and significant estimated elasticity. On the contrary, the lag of the closeness to the frontier fails to yields a significant coefficient in that model, though it appears with a significant impact in comumn [3]. The difference is probably due to the big loss of individuals (and efficiency) in the model with full controls.

\begin{tabular}{|c|c|c|c|c|}
\hline $\begin{array}{l}\text { Dependent variable: R\&D } \\
\text { Regulation proxy: Reg }\end{array}$ & $\begin{array}{l}\text { nsity }(R \& D \\
\text { ory Provisi } \\
\text { [1] }\end{array}$ & $\begin{array}{l}\text { - Within C } \\
\text { n Services } \\
\text { [2] }\end{array}$ & $\begin{array}{l}\text { p estimator } \\
\text { GREF) } \\
\text { [3] }\end{array}$ & [4] \\
\hline R\&D Spillovers & $\begin{array}{l}0.146^{* * \star} \\
(0.047)\end{array}$ & $\begin{array}{l}0.205^{\star \star \star} \\
(0.042)\end{array}$ & $\begin{array}{l}0.226^{\star \star \star *} \\
(0.039)\end{array}$ & $\begin{array}{l}0.364^{* \star \star} \\
(0.066)\end{array}$ \\
\hline REGREF & $\begin{array}{l}0.264^{\star \star *} \\
(0.082)\end{array}$ & $\begin{array}{c}0.047 \\
(0.070)\end{array}$ & $\begin{array}{c}0.011 \\
(0.066)\end{array}$ & $\begin{array}{l}-0.384^{\star \star \star *} \\
(0.105)\end{array}$ \\
\hline REGREF $\times$ HT & & $\begin{array}{l}0.663^{* \star *} \\
(0.094)\end{array}$ & $\begin{array}{l}0.705^{\star \star \star} \\
(0.089)\end{array}$ & $\begin{array}{l}0.817^{\star \star \star} \\
(0.123)\end{array}$ \\
\hline Closeness to Frontier (t-1) & & & $\begin{array}{l}0.087 \\
(0.058)\end{array}$ & $\begin{array}{c}0.030 \\
(0.057)\end{array}$ \\
\hline $\mathrm{K} / \mathrm{L}$ & & & & $\begin{array}{l}0.160^{* *} \\
(0.079)\end{array}$ \\
\hline Financial Assets & & & & $\begin{array}{l}0.131^{*} \\
(0.077)\end{array}$ \\
\hline REGREF on HT industries (marginal effect) & & $\begin{array}{l}0.709^{\star \star \star *} \\
(0.119)\end{array}$ & $\begin{array}{l}0.716^{* \star *} \\
(0.114)\end{array}$ & $\begin{array}{l}0.433^{\star \star \star} \\
(0.147)\end{array}$ \\
\hline year dummies & Yes & Yes & Yes & Yes \\
\hline Number of Obs & 2756 & 2756 & 2743 & 1110 \\
\hline Number of groups & 189 & 189 & 189 & 98 \\
\hline \multicolumn{5}{|c|}{$\begin{array}{l}\text { Note: Huber-White corrected standard errors in parentheses } \\
\text { All variables in natural logs, except } \mathrm{HT} \text { (dummy) }\end{array}$} \\
\hline
\end{tabular}

Table 1.

The so called "knock-on" effect of non-manufacturing regulation on manufacturing activities are captured by the regulation proxy REGIMP. This policy indicator is constructed accordingly to the "use" of non-manufacturing sectors in manufacturing. It gives then a measure of the regulatory constraints on the input side of production. The advantage is that it provides more variance as it is available in time-series cross-section data. Results are presented in Table 2. As before, the impact of $R \& D$ spillover on $R \& D$ intensity is significant in all specifications. Further, in non-HT industries regulation does not account for a significant effect on R\&D intensity. This time this is observed in all columns. However, once the interaction is considered, one observes the positive effect of regulation on $\mathrm{R} \& \mathrm{D}$ intensity in HT industries. This is true in relative and absolute terms. For both the interaction term and the overall marginal effect of regulation on HT manufacturing, the estimated coefficients are positive and significant in all specification.

The sign of the rest of controls are very similar than before. However, financial deepness fails to yield a significant effect. 


\begin{tabular}{|c|c|c|c|c|}
\hline \multicolumn{5}{|c|}{$\begin{array}{l}\text { Dependent variable: R\&D intensity (R\&D/VA) - Within Group estimator } \\
\text { Regulation proxy: "Knock on" effect of non-manufacturing regulation (REGIMP) }\end{array}$} \\
\hline $\begin{array}{ll}\text { R\&D Spillovers } \\
\end{array}$ & $\begin{array}{l}0.159^{* * *} \\
(0.048)\end{array}$ & $\begin{array}{l}0.204^{* * *} \\
(0.044)\end{array}$ & $\begin{array}{l}0.225^{* * *} \\
(0.041)\end{array}$ & $\begin{array}{l}0.342^{* * *} \\
(0.069)\end{array}$ \\
\hline REGIMP & $\begin{array}{l}-0.026 \\
(0.129)\end{array}$ & $\begin{array}{l}-0.175 \\
(0.125)\end{array}$ & $\begin{array}{l}-0.179 \\
(0.125)\end{array}$ & $\begin{array}{l}-0.300 \\
(0.221)\end{array}$ \\
\hline REGIMP $\times$ HT & & $\begin{array}{l}1.533^{\star \star *} \\
(0.260)\end{array}$ & $\begin{array}{l}1.720^{\star \star \star \star} \\
(0.231)\end{array}$ & $\begin{array}{l}1.558^{* \star *} \\
(0.288)\end{array}$ \\
\hline Closeness to Frontier (t-1) & & & $\begin{array}{l}0.105^{*} \\
(0.060)\end{array}$ & $\begin{array}{c}0.043 \\
(0.057)\end{array}$ \\
\hline $\mathrm{K} / \mathrm{L}$ & & & & $\begin{array}{l}0.161^{* *} \\
(0.082)\end{array}$ \\
\hline Financial Assets/ GDP & & & & $\begin{array}{c}0.115 \\
(0.084)\end{array}$ \\
\hline REGIMP on HT industries (marginal effect) & & $\begin{array}{l}1.358^{* * *} \\
(0.291)\end{array}$ & $\begin{array}{l}1.541^{* \star *} \\
(0.256)\end{array}$ & $\begin{array}{l}1.258^{* * *} \\
(0.337)\end{array}$ \\
\hline year dummies & Yes & Yes & Yes & Yes \\
\hline Number of Obs & 2756 & 2756 & 2743 & 1110 \\
\hline Number of groups & 189 & 189 & 189 & 98 \\
\hline $\begin{array}{l}\text { Note: Huber-White corrected standard errors } \\
\text { All variables in natural logs, except HT (dum }\end{array}$ & arentheses & & & \\
\hline
\end{tabular}

Table 2.

Results are slightly different for the product market regulation proxy (PMR). PMR is an aggregate of economy-wide indicators aiming at capture market barriers. It does not vary in every period. We dispose of two surveys (2 points in time) distributed in the sample. This is probably the main reason for some changes in the estimations. Table 3 presents the results. Now the effect of regulation in the simple model (column [1]) appear to be negative and significant. This is also true for the effect of regulation in nonHT technologies in column [2] and [3], but the significance is not attained when further controls are included (column [4]). Interestingly, a positive and significant interaction between regulation and HT industries still shows up in these regressions. While the result of additional R\&D incentives induced by regulation in HT industries still holds, the addition of the positive and the negative part of regulation consequences yields a non significant overall marginal effect of regulation on HT industries.

Again a change of sign and significance is observed for the closeness to frontier. In general, the level of significance of the controls in these PMR regressions does not allow further conclusions. 


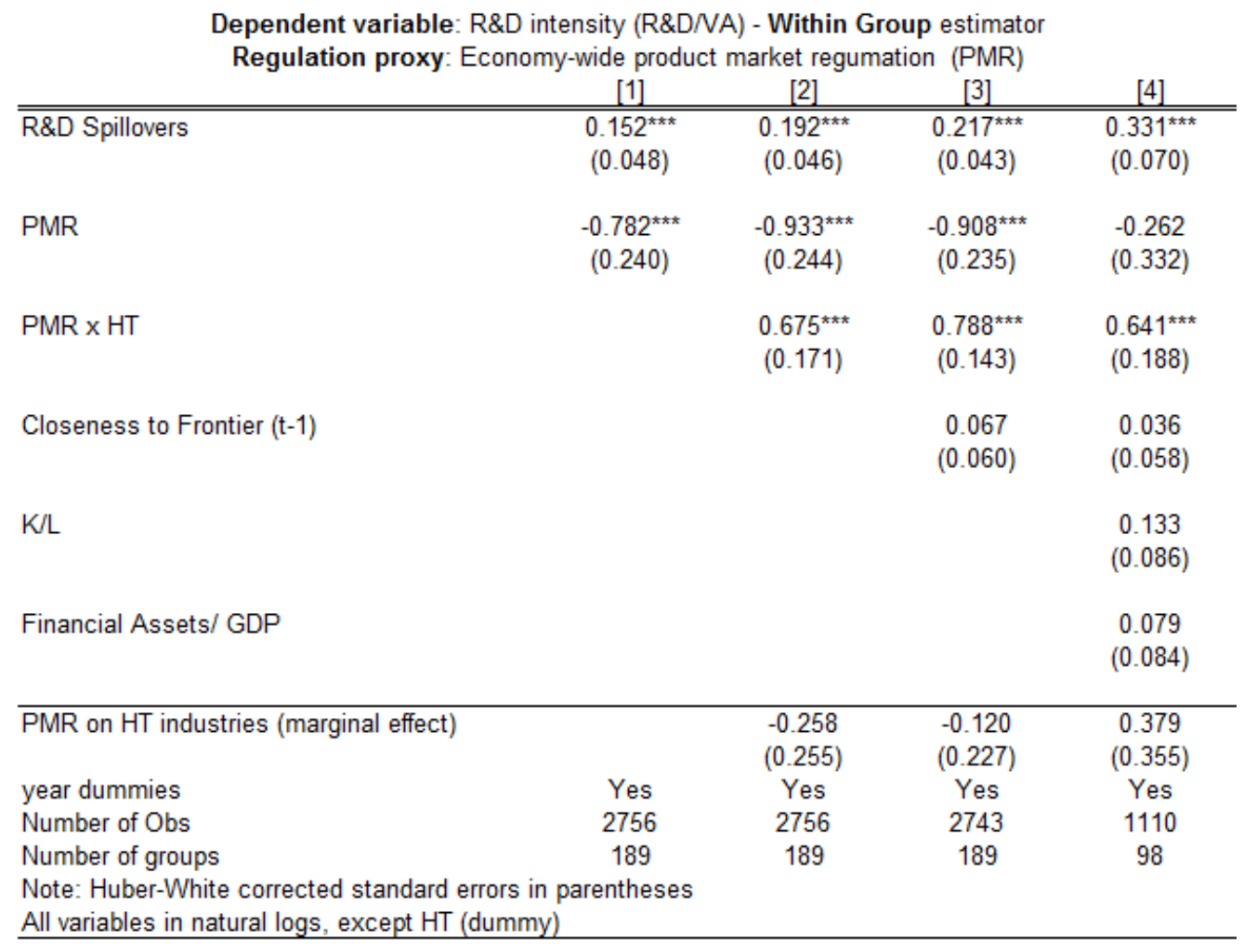

Table 3 .

Among market barriers summarised in PMR, one important indicators is the size of public sector enterprise (PMR-Public). One should expect that a higher and active scope of the state in manufacturing impose higher regulation, namely in the production of new varieties. Table 4 shows the results considering PMR-Public. The effect of regulation in the simple model is again positive and significant (column [1]). Similarly, once the interaction is considered, the effect of PMR Public alone (the impact of regulation on $\mathrm{R} \& \mathrm{D}$ in non-HT industries) is non significant. Concerning our estimates of interest, we observe again that the interaction variable has a positive and significant coefficient in almost all specifications. In column [4] (full set of controls), however, the significance is ensured only at $10 \%$. The overall marginal effect of regulation on HT industries is positive and significant as before. The estimates related to the rest of controls are similar than in PMR regressions. 


\begin{tabular}{|c|c|c|c|c|}
\hline \multicolumn{5}{|c|}{$\begin{array}{l}\text { Dependent variable: R\&D intensity (R\&D/VA) - Within Group estimator } \\
\text { Regulation proxy: Size of Public Sector Entrprise (PMR Public) }\end{array}$} \\
\hline & [1] & [2] & [3] & [4] \\
\hline R\&D Spillovers & $\begin{array}{l}0.155^{* * *} \\
(0.054)\end{array}$ & $\begin{array}{l}0.190^{* \star *} \\
(0.052)\end{array}$ & $\begin{array}{l}0.217^{* \star *} \\
(0.049)\end{array}$ & $\begin{array}{l}0.318^{* \star \star} \\
(0.071)\end{array}$ \\
\hline PMR Public & $\begin{array}{l}0.555^{* *} \\
(0.250)\end{array}$ & $\begin{array}{c}0.147 \\
(0.250)\end{array}$ & $\begin{array}{c}0.193 \\
(0.245)\end{array}$ & $\begin{array}{c}0.371 \\
(0.321)\end{array}$ \\
\hline PMR Public $\times \mathrm{HT}$ & & $\begin{array}{l}1.566^{\star \star *} \\
(0.551)\end{array}$ & $\begin{array}{l}2.011^{\star \star \star \star} \\
(0.470)\end{array}$ & $\begin{array}{r}0.818^{*} \\
(0.418)\end{array}$ \\
\hline Closeness to Frontier (t-1) & & & $\begin{array}{c}0.086 \\
(0.064)\end{array}$ & $\begin{array}{c}0.044 \\
(0.058)\end{array}$ \\
\hline $\mathrm{K} / \mathrm{L}$ & & & & $\begin{array}{c}0.113 \\
(0.085)\end{array}$ \\
\hline Financial Assets/ GDP & & & & $\begin{array}{c}0.107 \\
(0.079)\end{array}$ \\
\hline PMR Public on HT industries (marginal effect) & & $\begin{array}{l}1.713^{\star \star *} \\
(0.531)\end{array}$ & $\begin{array}{l}2.204^{\star \star \star *} \\
(0.469)\end{array}$ & $\begin{array}{l}1.189^{* \star *} \\
(0.396)\end{array}$ \\
\hline year dummies & Yes & Yes & Yes & Yes \\
\hline Number of Obs & 2548 & 2548 & 2535 & 1110 \\
\hline Number of groups & 176 & 176 & 176 & 98 \\
\hline $\begin{array}{l}\text { Note: Huber-White corrected standard errors in } \\
\text { All variables in natural logs, except HT (dummy }\end{array}$ & arentheses & & & \\
\hline
\end{tabular}

Table 4.

Overall, these results are in line with the main model prediction regarding the Schumpetrian equilibrium. As regulation increase, the dissuasive effect of defensive strategies of the leaders can be reduced. As a consequence, R\&D incentives are higher, but the final effect regulation is always modulated by the size of innovation since it shapes monopolist incentives. This prediction implies that the positive effect of regulation should empirically be found when the size of innovation is higher. This is what the interaction term and the overall marginal effect of regulation on HT industries confirm for almost all regressions.

One may argue that our time-series cross-section data structure implies intra-group correlation. Thus, we run all regressions using clustered Huber-White correction of standard errors. Results are presented in Tables 5 to 8 (in appendix). Concerning the interaction term, most of the previous results are preserved. Namely, for the time varying indicators REGREF and REGIMP, the sign of the estimate is positive and significant in all regressions. The significance of the overall marginal effect of regulation on $R \& D$ in HT also remain mostly positive and significant. As before, the lack of significance of this estimate still appears in PMR regressions, but not in PMR-Public.

As an additional robustness check we redefine the HT dummy variable to incorporate other activities using intensively ICT industries as suppliers. We namely include industries 29 (machinery and equipment) and motor vehicles (34). We show the results in Tables 9 to 12 (in the appendix). Here again, the main argument of the model is confirmed: the coefficient of the interaction term is still positive and significant for most of specifications and indicators. This time however, in PMR regressions, a negative effect appears in the overall marginal effect of regulation on R\&D intensity in HT industries. In the rest of regressions, using more efficient proxies of regulation, the positive and significant is still observed. 
Finally, in order to test in further detail our theoretical setting we use data from firm demography provided by the OECD firm-level project (Scarpetta et al. 2002). We regress the entry rate on regulation and plausible controls such as the level of capital stock to proxy for sunk fixed costs and the level of production in the industry as a proxy of market size (Table 13, appendix). To avoid multicollinearity issues we only use our timevarying indicators REGREF and REGIMP. We run within group regressions and observe contrasted results. While for REGREF (regulation in network services) the correlation is negative for the REGIMP indicator a positive and significant coefficient appears. Giving that the latter should be more efficient because of its panel data availability and that the magnitude is quite important, a nontrivial link between de jure and de facto dimensions of competition appears. Our explanation may help to understand this outcome.

\section{Conclusion}

We have shown in a simple quality-ladders model the consequences of defensive innovation strategies on R\&D effort and market structure. Among available strategies, defensive reactions may render $R \& D$ more costly and reduce the incentives to innovate. Institutions constraining this set of strategies and reducing its deterring effects may increase the resources devoted to innovation and also the number of active $R \& D$ race participants.

The evolution of R\&D expenditure in OECD industries confirms these results, specially for time-varying indicators of market regulation. In general, regressions provide clear results. In most specifications, regulation positively influences R\&D in high-technology industries and its effect is clearly higher relative to the rest of industries.

Despite data limitation on R\&D and the simple framework of the model, the core message seems clear: Defensive reactions in manufacturing, hard to enforce and more or less limited by market regulation, raise the question about the role of market institutions steering rivalry externalities.

Notice that industry-level evidence is useful since it exploits the consequences of different competitive environments. In that sense, further efforts can be addressed to check the robustness of our results by using alternative measures of performance and more detailed indicators of regulation, as well as by getting further insight with firm demographic data at the industry level.

\section{Appendix}

\subsection{Proofs of theoretical propositions}

\subsubsection{Proof of proposition 1}

The necessity of this condition comes from the fact that any credible commitment of a high R\&D effort depends on the capability of the leader to perform, at least, a positive amount of R\&D when free entry is possible. Equation (13) shows that the leader firm does perform $\mathrm{R} \& \mathrm{D}$ when $\Lambda_{L}\left[v_{L}\left(j_{\omega}+1\right)-v_{L}\left(j_{\omega}\right)\right] \geq 1$. If free entry applies, then $v_{L}\left(j_{\omega}+1\right)=\frac{1}{\Lambda_{o}}$. Since $\Lambda_{o}\left(\theta_{j_{\omega}}\right)$ is a function of $\delta\left(j_{\omega}+1\right) \equiv \gamma^{\left[j_{\omega}+1\right][\sigma-1]}$, we can obtain $v_{L}\left(j_{\omega}\right)$ by adjusting for one step down in the quality-ladder: $v_{L}\left(j_{\omega}\right)=\frac{\gamma^{-[\sigma-1]}}{\Lambda_{o}\left(\theta_{j_{\omega}-1}\right)}$. Putting 
these elements together yields the credibility condition (14). Moreover, because of constant returns to scale of the R\&D investment, if (14) holds as an strict inequality, the optimal R\&D effort for the leader is unbounded. If (14) holds as equality, the leader can perform any finite amount of $\mathrm{R} \& \mathrm{D}$ effort. In both cases it can invest a positive amount in $\mathrm{R} \& \mathrm{D}$ without taking into account outsiders menace.

\subsubsection{Proof of proposition 2}

Recalling that $\frac{\Lambda_{L}}{\Lambda_{o}(\theta)}=\frac{1}{\cos ^{\xi} \theta}$ and using (14) for $\theta_{j_{\omega}}=\theta$ inmediatly gives (19). Further, by equation (12), the absence of outsiders in $\mathrm{R} \& \mathrm{D}$ races requires $v_{L}\left(j_{\omega}+1\right)<\frac{1}{\Lambda_{o}\left(\theta_{j \omega}\right)}$. Consider the optimal value of the next innovation $v_{L}\left(j_{\omega}+1\right)$ by using (17), profits $(7)$ and the definition of $\Lambda_{o}\left(\theta_{j_{\omega}}\right)$. This inequality is then equivalent to: $\frac{\delta\left(j_{\omega}+1\right)-\Theta}{\left[1-\gamma^{-[\sigma-1]}\right]}<\frac{\delta\left(j_{\omega}+1\right)}{\cos ^{\xi} \theta}$, where $\Theta \equiv \frac{c(\theta, \psi)}{\frac{p-1}{p} \frac{E(t) L(t)}{Q(t)}}$. Now consider condition (14) for a constant value of bias : $\frac{1}{\left[1-\gamma^{-[\sigma-1]}\right]}$ $<\frac{1}{\cos ^{\xi} \theta}$. After multiplying both sides of the latter inequality by $\delta\left(j_{\omega}+1\right)$, since $\Theta>0$ it immediately appears that credibility condition ensures the absence of outsiders in $R \& D$ races.

\subsubsection{Proof of proposition 3}

By the maximum principle, the choice of $\theta_{j_{\omega}}$, is determined by the first order condition of the RHS of (21). To do so, we use $c\left(\theta_{j_{\omega}}, \psi\right)$ as defined by (9). Recall also that the free entry condition in the precedent $R \& D$ race (the one that the incumbent has won) states: $v_{L}\left(j_{\omega}\right)=\frac{1}{\Lambda_{o}\left(j_{\omega}, \theta_{j_{\omega}-1}\right)}=\frac{1}{\Lambda_{L}\left(j_{\omega}\right) \cos ^{\xi} \theta_{j_{\omega}-1}}$ where $\Lambda_{o}\left(j_{\omega}, \theta_{j_{\omega}-1}\right)$ and $\Lambda_{L}\left(j_{\omega}\right)$ are the outsiders and the leader $R \& D$ productivity in the preceding $R \& D$ race, respectively. After applying this, first order condition can be written as $\cos \theta_{j_{\omega}}=\cos ^{\frac{\xi}{\xi+\psi}} \theta_{j_{\omega}-1}\left[\frac{\psi f}{\xi I_{0 L}}\right]^{\frac{1}{\xi+\psi}}$. Define now $q \equiv\left(\frac{\psi f}{\xi I_{0 L}}\right)^{\frac{1}{\xi+\psi}} ; \beta \equiv \frac{\xi}{\xi+\psi}<1 ; a_{j_{\omega}} \equiv \cos \theta_{j_{\omega}}$. The sequence of $a_{j_{\omega}}$ can be expressed as $a_{j_{\omega}}=q^{z\left(j_{\omega}\right)}$ where $z\left(j_{\omega}\right)=\sum_{j=1}^{j_{\omega}} \beta^{j}$ is itself a geometric sequence that converges towards $\frac{1}{1-\beta}$. Thus, for a high enough level of $j_{\omega}$, one has $a=q^{\frac{1}{1-\beta}}$. Putting back the definitions of $a, q$ and $\beta$ gives directly (22).

\subsubsection{Proof of proposition 4}

The value $\bar{\psi}$ defined above is the one solving $\cos ^{\xi} \theta=\left[1-\gamma^{-[\sigma-1]}\right]$. Denote $\Omega(\psi) \equiv$ $\cos ^{\xi} \theta=\left[\frac{\left[\gamma^{\sigma-1}-1\right] \psi f}{\xi n}\right]^{\frac{\xi}{\psi-\xi}}$ and $\Psi \equiv\left[1-\gamma^{-[\sigma-1]}\right]$. To prove proposition 4, we need to show that $\Omega(\psi)$ intercepts $\Psi$ once for $\cos \theta \in] 0 ; 1]$. We show first that $\Omega$ is an increasing function of $\psi$. Taking partial derivates gives:

$$
\frac{\partial \Omega(\psi)}{\partial \psi}=\frac{-\xi}{\psi[\xi-\psi]^{2}}\left[\frac{\left[\gamma^{\sigma-1}-1\right] \psi f}{\xi n}\right]^{\frac{\xi}{\xi-\psi}}\left[\xi-\psi+\psi \ln \left[\frac{\left[\gamma^{\sigma-1}-1\right] \psi f}{\xi n}\right]\right] .
$$

Since $\left.\left.\cos ^{\xi} \theta=\left[\frac{\left[\gamma^{\sigma-1}-1\right] \psi f}{\xi n}\right]^{\frac{\xi}{\psi-\xi}} \in\right] 0 ; 1\right]$ and $\psi>\xi$, the sign of the term in the brakets at the right-hand end is negative. Thus $\frac{\partial \Omega(\psi)}{\partial \psi}>0$, which means that $\Omega(\psi)$ is a 
monotonically increasing function of $\psi$. On the other hand, the term $\Psi$ does not vary along with $\psi$. Furthermore, for $\gamma>0$ and $\sigma>1$ (the standard parameter) we verify $\Psi<1$. Hence, for relevant values of $\cos \theta$ there exists a unique intercept for $\Omega$ and $\Psi$. Figure 4.2 illustrate this proof.

\subsubsection{Proof of proposition 5}

By simple inspection of (31) one verifies that $s_{r}$ is increasing in $\psi$. Analyically, using price setting $p=\gamma$ and (31) we evaluate the effect of $\psi$ on $s_{r}$ as $\frac{\partial s_{r}}{\partial \psi}=\frac{n^{2}[\gamma-1] \gamma^{2+\sigma} \xi}{\left[\gamma^{\sigma} \psi[n[\gamma-1]+\rho]+\gamma[n[\gamma \xi+\psi]-\rho \psi]\right]^{2}}>$ 0 . To understand the effect of the size of innovation note that the multiplicative factor of $\psi$ in $(31)$ is $\gamma^{\sigma-1}\left[1-\frac{1}{\gamma}\right]$, which is increasing in $\gamma$. Although crossed derivates can be computed, for the sake of presentation we show numerical simulations. Figure 4.3 plots $\frac{\partial s_{r}}{\partial \psi}$ for different values of $\gamma$. The shape of the curve does not change for a large set of parameters values provided that $\gamma<\frac{\sigma}{\sigma-1}$ and $n<\rho$ (the standard intertemporal assumption).

\subsubsection{Proof of proposition 6}

$$
\begin{aligned}
& \frac{\partial s_{r m}}{\partial \psi}=\frac{f\left[1-\gamma^{-(\sigma-1)}\right]^{1-\frac{\psi}{\xi}} \ln \left[1-\gamma^{-(\sigma-1)}\right]}{n \xi\left[1+\frac{f}{n}\left[1-\gamma^{-(\sigma-1)}\right]^{1-\frac{\psi}{\xi}}+\frac{\rho}{n[\gamma-1]}\right]}<0 \text { since } 0<1-\gamma^{-(\sigma-1)}<1 \text {. Thus, } s_{r m} \text { is decreasing } \\
& \text { in } \psi \text {. }
\end{aligned}
$$

\begin{tabular}{|c|c|c|c|c|}
\hline \multicolumn{5}{|c|}{$\begin{array}{l}\text { Dependent variable: R\&D intensity (R\&D/VA) - Within Group estimator } \\
\text { Regulation proxy: Regulatory Provisions in Services (REGREF) }\end{array}$} \\
\hline & [1] & [2] & [3] & [4] \\
\hline R\&D Spillovers & $\begin{array}{l}0.146^{*} \\
(0.079)\end{array}$ & $\begin{array}{l}0.205^{\star \star \star} \\
(0.071)\end{array}$ & $\begin{array}{l}0.226^{* \star *} \\
(0.062)\end{array}$ & $\begin{array}{l}0.364^{* \star *} \\
(0.104)\end{array}$ \\
\hline REGREF & $\begin{array}{c}0.264 \\
(0.198)\end{array}$ & $\begin{array}{c}0.047 \\
(0.147)\end{array}$ & $\begin{array}{c}0.011 \\
(0.139)\end{array}$ & $\begin{array}{l}-0.384^{*} \\
(0.205)\end{array}$ \\
\hline REGREF $\times$ HT & & $\begin{array}{l}0.663^{\star \star \star} \\
(0.231)\end{array}$ & $\begin{array}{l}0.705^{\star \star \star} \\
(0.226)\end{array}$ & $\begin{array}{l}0.817^{\star * \star} \\
(0.221)\end{array}$ \\
\hline Closeness to Frontier ( $\mathrm{t}-1)$ & & & $\begin{array}{l}0.087 \\
(0.130)\end{array}$ & $\begin{array}{c}0.030 \\
(0.106)\end{array}$ \\
\hline $\mathrm{K} / \mathrm{L}$ & & & & $\begin{array}{c}0.160 \\
(0.144)\end{array}$ \\
\hline Financial Assets & & & & $\begin{array}{c}0.131 \\
(0.127)\end{array}$ \\
\hline REGREF on HT industries (marginal effect) & & $\begin{array}{l}0.709^{* *} \\
(0.301)\end{array}$ & $\begin{array}{l}0.716^{* *} \\
(0.290)\end{array}$ & $\begin{array}{c}0.433 \\
(0.264)\end{array}$ \\
\hline year dummies & Yes & Yes & Yes & Yes \\
\hline Number of Obs & 2756 & 2756 & 2743 & 1110 \\
\hline Number of groups & 189 & 189 & 189 & 98 \\
\hline $\begin{array}{l}\text { Note: Clustered Huber-White corrected stand } \\
{ }^{\star} p<0.10,{ }^{\star \star} p<0.05,{ }^{\star \star \star} p<0.01 \text {; All variables }\end{array}$ & $\begin{array}{l}\text { errors in } \\
\text { tural log }\end{array}$ & $\begin{array}{l}\text { heses } \\
\text { ept HT (du }\end{array}$ & & \\
\hline
\end{tabular}

\subsubsection{Robustness check 1: clustered corrected standard errors}

Table 5. 
Dependent variable: R\&D intensity (R\&D/VA) - Within Group estimator

Regulation proxy: "Knock on" effect of non-manufacturing regulation (REGIMP)

\begin{tabular}{|c|c|c|c|c|}
\hline & [1] & [2] & [3] & [4] \\
\hline R\&D Spillovers & $\begin{array}{l}0.159^{*} \\
(0.081)\end{array}$ & $\begin{array}{l}0.204^{* \star \star} \\
(0.073)\end{array}$ & $\begin{array}{l}0.225^{* * *} \\
(0.064)\end{array}$ & $\begin{array}{l}0.342^{* \star \star} \\
(0.108)\end{array}$ \\
\hline REGIMP & $\begin{array}{l}-0.026 \\
(0.257)\end{array}$ & $\begin{array}{l}-0.175 \\
(0.255)\end{array}$ & $\begin{array}{l}-0.179 \\
(0.257)\end{array}$ & $\begin{array}{l}-0.300 \\
(0.369)\end{array}$ \\
\hline REGIMP $\times$ HT & & $\begin{array}{l}1.533^{\star \star *} \\
(0.588)\end{array}$ & $\begin{array}{l}1.720^{\star \star *} \\
(0.560)\end{array}$ & $\begin{array}{l}1.558^{\star \star *} \\
(0.574)\end{array}$ \\
\hline Closeness to Frontier (t-1) & & & $\begin{array}{l}0.105 \\
(0.138)\end{array}$ & $\begin{array}{c}0.043 \\
(0.102)\end{array}$ \\
\hline $\mathrm{K} / \mathrm{L}$ & & & & $\begin{array}{l}0.161 \\
(0.147)\end{array}$ \\
\hline Financial Assets/ GDP & & & & $\begin{array}{c}0.115 \\
(0.135)\end{array}$ \\
\hline REGIMP on HT industries (marginal effect) & & $\begin{array}{l}1.358^{* *} \\
(0.629)\end{array}$ & $\begin{array}{l}1.541^{\star \star \star \star} \\
(0.589)\end{array}$ & $\begin{array}{l}1.258^{*} \\
(0.643)\end{array}$ \\
\hline year dummies & Yes & Yes & Yes & Yes \\
\hline Number of Obs & 2756 & 2756 & 2743 & 1110 \\
\hline Number of groups & 189 & 189 & 189 & 98 \\
\hline \multicolumn{5}{|c|}{$\begin{array}{l}\text { Note: Clustered Huber-White corrected standard errors in parentheses } \\
{ }^{*} p<0.10,{ }^{* \star} p<0.05,{ }^{* \star *}{ }^{*} p<0.01 ; \text { All variables in natural logs, except HT (dummy) }\end{array}$} \\
\hline
\end{tabular}

Table 6.

\begin{tabular}{|c|c|c|c|c|}
\hline \multicolumn{5}{|c|}{$\begin{array}{l}\text { Dependent variable: R\&D intensity (R\&D/VA) - Within Group estimator } \\
\text { Regulation proxy: Economy-wide product market regumation (PMR) }\end{array}$} \\
\hline & [1] & [2] & [3] & [4] \\
\hline R\&D Spillovers & $\begin{array}{l}0.152^{*} \\
(0.081)\end{array}$ & $\begin{array}{l}0.192^{* *} \\
(0.075)\end{array}$ & $\begin{array}{l}0.217^{\star \star \star *} \\
(0.066)\end{array}$ & $\begin{array}{l}0.331^{* * *} \\
(0.107)\end{array}$ \\
\hline PMR & $\begin{array}{l}-0.782^{*} \\
(0.415)\end{array}$ & $\begin{array}{l}-0.933^{* *} \\
(0.430)\end{array}$ & $\begin{array}{l}-0.908^{* \star} \\
(0.408)\end{array}$ & $\begin{array}{l}-0.262 \\
(0.400)\end{array}$ \\
\hline \multicolumn{2}{|l|}{ PMR $\times$ HT } & $\begin{array}{l}0.675^{\star *} \\
(0.310)\end{array}$ & $\begin{array}{l}0.788^{\star \star *} \\
(0.266)\end{array}$ & $\begin{array}{l}0.641^{\star * * *} \\
(0.244)\end{array}$ \\
\hline \multicolumn{2}{|l|}{ Closeness to Frontier ( $t-1)$} & & $\begin{array}{l}0.067 \\
(0.139)\end{array}$ & $\begin{array}{l}0.036 \\
(0.101)\end{array}$ \\
\hline \multicolumn{2}{|l|}{$\mathrm{K} / \mathrm{L}$} & & & $\begin{array}{c}0.133 \\
(0.156)\end{array}$ \\
\hline \multicolumn{2}{|l|}{ Financial Assets/ GDP } & & & $\begin{array}{c}0.079 \\
(0.135)\end{array}$ \\
\hline \multicolumn{2}{|l|}{ PMR on $\mathrm{HT}$ industries (marginal effect) } & $\begin{array}{l}-0.258 \\
(0.423)\end{array}$ & $\begin{array}{l}-0.120 \\
(0.377)\end{array}$ & $\begin{array}{c}0.379 \\
(0.438)\end{array}$ \\
\hline year dummies & Yes & Yes & Yes & Yes \\
\hline Number of Obs & 2756 & 2756 & 2743 & 1110 \\
\hline Number of groups & 189 & 189 & 189 & 98 \\
\hline \multicolumn{5}{|c|}{$\begin{array}{l}\text { Note: Clustered Huber-White corrected standard errors in parentheses } \\
{ }^{\star} p<0.10,{ }^{\star \star} p<0.05,{ }^{\star \star \star}{ }^{\star *} p<0.01 \text {; All variables in natural logs, except HT (dummy) }\end{array}$} \\
\hline
\end{tabular}

Table 7. 
Dependent variable: R\&D intensity (R\&D/NA) - Within Group estimator Regulation proxy: Size of Public Sector Entrprise (PMR Public)

\begin{tabular}{|c|c|c|c|c|}
\hline 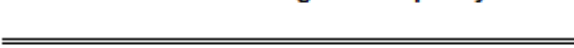 & [1] & [2] & {$[3]$} & [4] \\
\hline R\&D Spillovers & $\begin{array}{l}0.155^{*} \\
(0.090)\end{array}$ & $\begin{array}{l}0.190^{* *} \\
(0.085)\end{array}$ & $\begin{array}{l}0.217^{\star \star \star} \\
(0.076)\end{array}$ & $\begin{array}{l}0.318^{\star \star \star \star} \\
(0.110)\end{array}$ \\
\hline PMR Public & $\begin{array}{c}0.555 \\
(0.381)\end{array}$ & $\begin{array}{c}0.147 \\
(0.400)\end{array}$ & $\begin{array}{c}0.193 \\
(0.395)\end{array}$ & $\begin{array}{c}0.371 \\
(0.450)\end{array}$ \\
\hline PMR Public $x$ HT & & $\begin{array}{c}1.566 \\
(0.971)\end{array}$ & $\begin{array}{l}2.011^{\text {** }} \\
(0.849)\end{array}$ & $\begin{array}{c}0.818 \\
(0.565)\end{array}$ \\
\hline Closeness to Frontier (t-1) & & & $\begin{array}{c}0.086 \\
(0.150)\end{array}$ & $\begin{array}{c}0.044 \\
(0.101)\end{array}$ \\
\hline $\mathrm{K} / \mathrm{L}$ & & & & $\begin{array}{c}0.113 \\
(0.155)\end{array}$ \\
\hline Financial Assets/ GDP & & & & $\begin{array}{c}0.107 \\
(0.134)\end{array}$ \\
\hline PMR Public on HT industries (marginal effect) & & $\begin{array}{l}1.713^{*} \\
(0.892)\end{array}$ & $\begin{array}{c}2.204^{* \star \star} \\
(0.823)\end{array}$ & $\begin{array}{l}1.189^{\star *} \\
(0.513)\end{array}$ \\
\hline year dummies & Yes & Yes & Yes & Yes \\
\hline Number of Obs & 2548 & 2548 & 2535 & 1110 \\
\hline Number of groups & 176 & 176 & 176 & 98 \\
\hline
\end{tabular}

Table 8. 


\subsubsection{Robustness check 2: high technology definition}

\begin{tabular}{|c|c|c|c|c|}
\hline \multicolumn{5}{|c|}{$\begin{array}{l}\text { Dependent variable: R\&D intensity (R\&D/NA) - Within Group estimator } \\
\text { Regulation proxy: Regulatory Provisions in Services (REGREF) }\end{array}$} \\
\hline & [1] & [2] & [3] & [4] \\
\hline R\&D Spillovers & $\begin{array}{l}0.146^{* \star *} \\
(0.047)\end{array}$ & $\begin{array}{l}0.201^{* \star *} \\
(0.046)\end{array}$ & $\begin{array}{l}0.233^{* \star *} \\
(0.043)\end{array}$ & $\begin{array}{l}0.362^{* * *} \\
(0.072)\end{array}$ \\
\hline REGREF & $\begin{array}{l}0.264^{* \star *} \\
(0.082)\end{array}$ & $\begin{array}{c}0.046 \\
(0.073)\end{array}$ & $\begin{array}{l}-0.008 \\
(0.068)\end{array}$ & $\begin{array}{l}-0.355^{* * *} \\
(0.107)\end{array}$ \\
\hline REGREF $\times$ HT2 & & $\begin{array}{l}0.449^{\star \star \star *} \\
(0.072)\end{array}$ & $\begin{array}{l}0.505^{\star \star *} \\
(0.076)\end{array}$ & $\begin{array}{l}0.254^{* *} \\
(0.107)\end{array}$ \\
\hline Closeness to Frontier ( $\mathrm{t}-1)$ & & & $\begin{array}{l}0.125^{* *} \\
(0.063)\end{array}$ & $\begin{array}{c}0.071 \\
(0.060)\end{array}$ \\
\hline $\mathrm{K} / \mathrm{L}$ & & & & $\begin{array}{c}0.124 \\
(0.084)\end{array}$ \\
\hline Financial Assets & & & & $\begin{array}{c}0.106 \\
(0.079)\end{array}$ \\
\hline REGREF on HT2 industries (marginal effect) & & $\begin{array}{l}0.495^{\star \star \star} \\
(0.101)\end{array}$ & $\begin{array}{l}0.497^{\star \star \star} \\
(0.099)\end{array}$ & $\begin{array}{l}-0.101 \\
(0.152)\end{array}$ \\
\hline year dummies & Yes & Yes & Yes & Yes \\
\hline Number of Obs & 2756 & 2756 & 2743 & 1110 \\
\hline Number of groups & 189 & 189 & 189 & 98 \\
\hline $\begin{array}{l}\text { Note: Huber-White corrected standard errors i } \\
\text { All variables in natural logs, except HT2 (dum }\end{array}$ & irentheses & & & \\
\hline
\end{tabular}

Table 9. 
Dependent variable: R\&D intensity (R\&D/VA) - Within Group estimator

Regulation proxy: "Knock on" effect of non-manufacturing regulation (REGIMP)

\begin{tabular}{|c|c|c|c|c|}
\hline " & [1] & [2] & [3] & [4] \\
\hline R\&D Spillovers & $\begin{array}{l}0.159^{\star * \star} \\
(0.048)\end{array}$ & $\begin{array}{l}0.200^{* * *} \\
(0.047)\end{array}$ & $\begin{array}{l}0.231^{\star \star \star *} \\
(0.044)\end{array}$ & $\begin{array}{l}0.352^{* * *} \\
(0.072)\end{array}$ \\
\hline REGIMP & $\begin{array}{l}-0.026 \\
(0.129)\end{array}$ & $\begin{array}{l}-0.203 \\
(0.129)\end{array}$ & $\begin{array}{l}-0.230^{*} \\
(0.130)\end{array}$ & $\begin{array}{l}-0.215 \\
(0.220)\end{array}$ \\
\hline REGIMP x HT2 & & $\begin{array}{l}0.969^{\star * *} \\
(0.184)\end{array}$ & $\begin{array}{l}1.153^{\star \star \star *} \\
(0.187)\end{array}$ & $\begin{array}{l}0.681^{\star \star \star *} \\
(0.231)\end{array}$ \\
\hline Closeness to Frontier (t- 1$)$ & & & $\begin{array}{l}0.133^{\star \star} \\
(0.065)\end{array}$ & $\begin{array}{c}0.076 \\
(0.060)\end{array}$ \\
\hline $\mathrm{K} / \mathrm{L}$ & & & & $\begin{array}{c}0.133 \\
(0.085)\end{array}$ \\
\hline Financial Assets/ GDP & & & & $\begin{array}{c}0.107 \\
(0.085)\end{array}$ \\
\hline REGIMP on HT2 industries (marginal effect) & & $\begin{array}{c}0.766^{\star \star \star} \\
(0.210)\end{array}$ & $\begin{array}{l}0.922^{\star \star \star *} \\
(0.201)\end{array}$ & $\begin{array}{c}0.466 \\
(0.293)\end{array}$ \\
\hline year dummies & Yes & Yes & Yes & Yes \\
\hline Number of Obs & 2756 & 2756 & 2743 & 1110 \\
\hline $\begin{array}{l}\text { Number of groups } \\
\text { Note: Huber-White corrected standard errors } \\
\text { All variables in natural logs, except HT2 (dum }\end{array}$ & $\begin{array}{l}189 \\
\text { rentheses }\end{array}$ & 189 & 189 & 98 \\
\hline
\end{tabular}

Table 10.

Dependent variable: R\&D intensity (R\&D/VA) - Within Group estimator Regulation proxy: Economy-wide product market regumation (PMR)

\begin{tabular}{|c|c|c|c|c|}
\hline (l) & [1] & [2] & [3] & [4] \\
\hline R\&D Spillovers & $\begin{array}{l}0.152^{\star \star \star} \\
(0.048)\end{array}$ & $\begin{array}{c}0.182^{\star \star \star} \\
(0.047)\end{array}$ & $\begin{array}{c}0.210^{* * *} \\
(0.045)\end{array}$ & $\begin{array}{c}0.325^{\text {***}} \\
(0.071)\end{array}$ \\
\hline PMR & $\begin{array}{c}-0.782^{* * *} \\
(0.240)\end{array}$ & $\begin{array}{c}-0.958^{\star * *} \\
(0.252)\end{array}$ & $\begin{array}{c}-0.945^{\star * \star} \\
(0.244)\end{array}$ & $\begin{array}{c}-0.284 \\
(0.349)\end{array}$ \\
\hline PMR x HT2 & & $\begin{array}{c}0.476^{* * *} \\
(0.127)\end{array}$ & $\begin{array}{c}0.577^{\star \star *} \\
(0.122)\end{array}$ & $\begin{array}{l}0.311^{\star *} \\
(0.144)\end{array}$ \\
\hline Closeness to Frontier (t- 1$)$ & & & $\begin{array}{c}0.089 \\
(0.063)\end{array}$ & $\begin{array}{c}0.062 \\
(0.059)\end{array}$ \\
\hline $\mathrm{K} / \mathrm{L}$ & & & & $\begin{array}{c}0.130 \\
(0.087)\end{array}$ \\
\hline Financial Assets/ GDP & & & & $\begin{array}{c}0.079 \\
(0.084)\end{array}$ \\
\hline PMR on HT2 industries (marginal effect) & & $\begin{array}{c}-0.482^{* *} \\
(0.236)\end{array}$ & $\begin{array}{l}-0.368^{*} \\
(0.218)\end{array}$ & $\begin{array}{c}0.026 \\
(0.304)\end{array}$ \\
\hline year dummies & Yes & Yes & Yes & Yes \\
\hline Number of Obs & 2756 & 2756 & 2743 & 1110 \\
\hline $\begin{array}{l}\text { Number of groups } \\
\text { Note: Huber-White corrected standard err } \\
\text { All variables in natural logs, except } \mathrm{HT} 2\end{array}$ & $\begin{array}{l}189 \\
\text { rentheses }\end{array}$ & 189 & 189 & 98 \\
\hline
\end{tabular}

Table 11. 


\begin{tabular}{|c|c|c|c|c|}
\hline \multicolumn{5}{|c|}{$\begin{array}{l}\text { Dependent variable: R\&D intensity (R\&D/VA) - Within Group estimator } \\
\text { Regulation proxy: Size of Public Sector Entrprise (PMR Public) }\end{array}$} \\
\hline & [1] & [2] & [3] & [4] \\
\hline R\&D Spillovers & $\begin{array}{l}0.155^{* * *} \\
(0.054)\end{array}$ & $\begin{array}{l}0.179^{* * *} \\
(0.054)\end{array}$ & $\begin{array}{l}0.210^{* \star *} \\
(0.051)\end{array}$ & $\begin{array}{l}0.307^{* * \star} \\
(0.072)\end{array}$ \\
\hline PMR Public & $\begin{array}{l}0.555^{* *} \\
(0.250)\end{array}$ & $\begin{array}{c}0.142 \\
(0.277)\end{array}$ & $\begin{array}{l}0.158 \\
(0.275)\end{array}$ & $\begin{array}{c}0.481 \\
(0.359)\end{array}$ \\
\hline PMR Public $x$ HT2 & & $\begin{array}{l}1.005^{\star *} \\
(0.409)\end{array}$ & $\begin{array}{l}1.335^{\star \star \star} \\
(0.382)\end{array}$ & $\begin{array}{c}0.176 \\
(0.383)\end{array}$ \\
\hline Closeness to Frontier ( $\mathrm{t}-1)$ & & & $\begin{array}{c}0.105 \\
(0.068)\end{array}$ & $\begin{array}{c}0.050 \\
(0.059)\end{array}$ \\
\hline $\mathrm{K} / \mathrm{L}$ & & & & $\begin{array}{c}0.102 \\
(0.086)\end{array}$ \\
\hline Financial Assets/GDP & & & & $\begin{array}{c}0.110 \\
(0.079)\end{array}$ \\
\hline PMR Public on HT2 industries (marginal effect) & & $\begin{array}{l}1.147^{* * *} \\
(0.373)\end{array}$ & $\begin{array}{l}1.493^{* \star *} \\
(0.352)\end{array}$ & $\begin{array}{l}0.657^{* \star} \\
(0.324)\end{array}$ \\
\hline year dummies & Yes & Yes & Yes & Yes \\
\hline Number of Obs & 2548 & 2548 & 2535 & 1110 \\
\hline Number of groups & 176 & 176 & 176 & 98 \\
\hline $\begin{array}{l}\text { Note: Huber-White corrected standard errors in } \\
\text { All variables in natural logs, except } \mathrm{HT2} \text { (dummy }\end{array}$ & rentheses & & & \\
\hline
\end{tabular}

Table 12.

\section{$5.2 \quad$ Firm Entry}

Entry rate

\begin{tabular}{lcc}
\hline REGIMP & $1.421^{* * *}$ & \\
REGREF & $(0.252)$ & \\
& & $-0.476^{* * *}$ \\
CAPITAL STOCK & & $(0.166)$ \\
& 0.073 & $0.255^{*}$ \\
VALUE ADDED & $(0.131)$ & $(0.131)$ \\
& $0.113^{*}$ & -0.005 \\
year dummies & $(0.066)$ & $(0.066)$ \\
Number of Obs & Yes & Yes \\
Individuals & 584 & 584 \\
\hline
\end{tabular}

Note: Standard errors in parentheses

${ }^{*} \mathrm{p}<0.10,{ }^{* *} \mathrm{p}<0.05,{ }^{* * *} \mathrm{p}<0.01$

Table 13 


\subsection{Descriptive Statistics}

\begin{tabular}{lccc} 
Variable & Obs & Mean & Std. Dev. \\
\hline \hline R\&D / Added Value & 2852 & 0,104 & 0,527 \\
PMR & 5760 & 1,801 & 0,437 \\
REGREF & 6375 & 4,193 & 1,312 \\
PMR Public & 6375 & 3,015 & 1,280 \\
REGIMP & 6375 & 0,132 & 0,037 \\
Closeness to Frontier & 6043 & 56,946 & 23,458 \\
K/L (hours) & 2785 & 0,046 & 0,031 \\
Financial Assets/GDP & 4440 & 66,915 & 50,330 \\
\hline
\end{tabular}

Table 14

\section{References}

[1] Aghion P. and P. Howitt (1992). A model of growth through creative destruction. Econometrica. Vol. 60, No. 2, pp. 353-35.

[2] Amable B. (1996). Endogenous growth and cycles through radical and incremental innovation. Annales d'Economie et de Statistique, No 44, pp. 91-110.

[3] Amable B., Demmou L. and I. Ledezma (2007). Competition, Innovation and Distance to Frontier. Ceprepmap Working Paper.

[4] Arnold, J., G. Nicoletti and S. Scarpetta (2008). Regulation, Allocative Efficiency and Productivity in OECD Countries: Industry and Firm-Level Evidence, OECD Economics Department Working Papers, No. 616, OECD Publishing.

[5] Braumoeller B. 2004. Hypothesis testing and multiplicative interaction terms. International Organization, Vol. 58, No. 4, pp. 807-820.

[6] Cohen W., R. Nelson and J. Walsh (2002). Protecting their intellectual assets: appropriability conditions and why US manufacturing firms patent (or not). NBER Working Paper no. 7552.

[7] Cohen W., A. Goto, A. Nagata, R. Nelson and J. Walsh (2002). RÉD spillover, patents and the incentives to innovate in Japan and the United States. Research Policy/ vol. 31, pp. 1349-1367.

[8] Conway P. and G. Nicoletti (2006). Product Market regulation in the NonManufacturing Sector of OECD Countries: Measurements and Highlights. OECD Economics Department Working Paper No. 530, Paris: OECD.

[9] Conway P., V. Janod and G. Nicoletti (2006). Product Market Regulation in OECD Countries: 1998 to 2003. Economics Department. Working Papers No. 419, Paris: OECD. 
[10] Conway P., D. de Rosa, G. Nicoletti and F. Steiner (2006). Regulation, Competition, and Productivity Convergence. Economics Department Working Papers No. 509, Paris: OECD.

[11] Etro F. (2007) Competition, Innovation, and Antitrust. A Theory of Market Leaders and Its Policy Implications. Berlin: Springer Verlag.

[12] Crepon B. and E. Duguet(1997). Research and development, competition and innovation. Pseudo-maximum likelihood and simulated maximum likelihood methods applied to count data models with heterogeneity. Journal of Econometrics. Vol. 79, No. 2, pp. $355-378$.

[13] Dinopoulos E. and F. Sener (2007). New direction in schumpeterian growth theory. Forthcoming in Horst Hanusch and Andreas Pyka (eds.), Elgar Companion to NeoSchumpeterian Economics, Edward Elgar, Cheltenham.

[14] Etro F. (2008) Stackelberg Competition with Endogenous Entry. Economic Journal, Vol. 118 No. 4, 1670-1697.

[15] Dinopoulos E. and C. Syropoulos (2007). Rent protection as a barrier to innovation and growth. Economic Theory. Vol. 32, No. 1, pp. 309-332.

[16] Grossman G. and E. Helpman (1991a). Quality Ladders in the theory of growth. Review of Economic Studies. Vol. 58, No. 1, pp. 43-61.

[17] Grossman G. and E. Helpman (1991b). Quality Ladders and Product Cycles. The Quarterly Journal of Economics. Vol. 106, No. 2, pp 557-586.

[18] Inklaar R., M. Timmer and B. van Ark (2008). Market services productivity across Europe and the US. Economic Policy, No. 1, pp. 139-19

[19] Levin R., A. Klevorick, R. Nelson, S. Winter (1987). Appropriating the returns from industrial RED. BrookingsPapers on Economic Activity. pp. 783-820.

[20] Friedrich R. (1982). In defence of multiplicative terms in multiple regression equations. American Journal of Political Science. Vol. 26, No.4, pp. 797-833.

[21] Jones C. (1995). Time series tests of endogenous growth models. Quarterly Journal of Economics, Vol. 110, pp. 495-525.

[22] Li C. (2003). Endogenous growth without scale effects: comment. The American Economic Review. Vol. 93, No. 3., pp. 1009-1017.

[23] Mullahy J. (1999).Interaction effects and difference-in-difference estimation in loglinear models. Technical Working Paper NBER 245.

[24] Nicoletti G. and S. Scarpetta (2003). Regulation, productivity and growth: OECD evidence. Economic Policy Vol. 36, pp. 9-72.

[25] Plümper T. and V. Troeger (2007). Efficient estimation of time-invariant and rarely changing variables in finite sample panel analyses with unit fixed effects. Political Analysis, Vol. 15, No. 2, pp. 124-139. 
[26] Scarpetta S., P. Hemmings, T. Tressel and J. Woo (2002). The Role of Policy and Institutions for Productivity and Firm Dynamics: Evidence From Micro and Industry data. OECD Working Paper No. 329.

[27] Segerstrom P. (1998). Endogenous growth without scale effects. The American Economic Review. Vol. 88, No. 5., pp. 1290-1310.

[28] Segrestrom P. (2007). Intel Economics. International Economic Review. Vol. 93, No. 3., pp. 709-728.

[29] Thoenig M. and T. Verdier (2003). A theory of defensive skill-biased innovation and globalization. The American Economic Review. Vol. 93, No. 3., pp. 709-728.

[30] Young A. (1998). Growth without scale effects. Journal of Political Economy. Vol. 106, No. 1, pp. 41-63. 